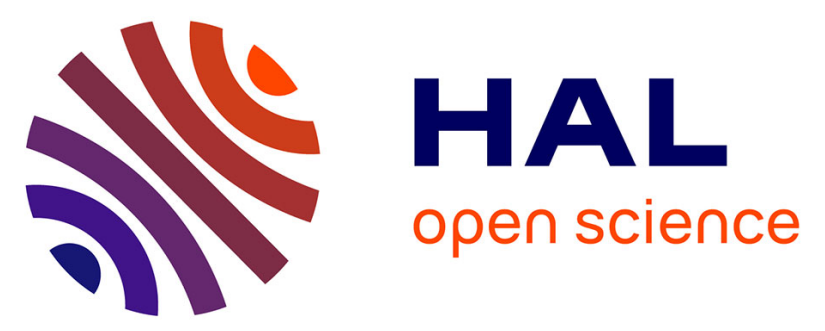

\title{
Influence of aperiodic non-tidal atmospheric and oceanic loading deformations on the stochastic properties of global GNSS vertical land motion time series
}

Kevin Gobron, Paul Rebischung, Michel van Camp, Alain Demoulin, Olivier Viron, Olivier de Viron

\section{To cite this version:}

Kevin Gobron, Paul Rebischung, Michel van Camp, Alain Demoulin, Olivier Viron, et al.. Influence of aperiodic non-tidal atmospheric and oceanic loading deformations on the stochastic properties of global GNSS vertical land motion time series. Journal of Geophysical Research: Solid Earth, 2021, 126 (9), 10.1029/2021JB022370 . hal-03449040

\author{
HAL Id: hal-03449040 \\ https://hal.science/hal-03449040
}

Submitted on 25 Nov 2021

HAL is a multi-disciplinary open access archive for the deposit and dissemination of scientific research documents, whether they are published or not. The documents may come from teaching and research institutions in France or abroad, or from public or private research centers.
L'archive ouverte pluridisciplinaire HAL, est destinée au dépôt et à la diffusion de documents scientifiques de niveau recherche, publiés ou non, émanant des établissements d'enseignement et de recherche français ou étrangers, des laboratoires publics ou privés. 


\title{
Influence of aperiodic non-tidal atmospheric and oceanic loading deformations on the stochastic properties of global GNSS vertical land motion time series
}

\author{
Kevin Gobron ${ }^{1,2,3}$, Paul Rebischung ${ }^{4,5}$, Michel Van Camp ${ }^{2}$, Alain \\ Demoulin $^{3,6}$ and Olivier de Viron $^{1}$ \\ ${ }^{1}$ LIENSs, UMR 7266, La Rochelle Université, CNRS, La Rochelle, France \\ ${ }^{2}$ Royal Observatory of Belgium, Uccle, Belgium \\ ${ }^{3}$ Department of Geography, University of Liège, Clos Mercator 3, Liège 4000 \\ ${ }^{4}$ Université de Paris, Institut de Physique du Globe de Paris, CNRS, IGN, Paris, France \\ ${ }^{5}$ ENSG-Géomatique, IGN, France \\ ${ }^{6}$ Fonds de la Recherche Scientifique F.R.S.-FNRS, Brussels, Belgium
}

\section{Key Points:}

- NTAOL deformations cause a latitudinal bias in parameter estimates of the white + power-law noise model usually describing GNSS time series.

- Removing NTAOL deformations corrects the latitudinal bias and dramatically reduces station velocity uncertainties at high latitudes.

- NTAOL deformations also introduce a seasonal spatial correlation in GNSS vertical land motion time series. 


\begin{abstract}
Monitoring vertical land motions (VLMs) at the level of $0.1 \mathrm{~mm} / \mathrm{yr}$ remains one of the most challenging scientific applications of global navigation satellite systems (GNSS). Such small rates of change can result from climatic and tectonic phenomena, and their detection is important to many solid Earth-related studies, including the prediction of coastal sea-level change and the understanding of intraplate deformation. Reaching a level of precision allowing to detect such small signals requires a thorough understanding of the stochastic variability in GNSS VLM time series. This paper investigates how the aperiodic part of non-tidal atmospheric and oceanic loading (NTAOL) deformations influences the stochastic properties of VLM time series. Using the time series of over 10,000 stations, we describe the impact of correcting for NTAOL deformation on 5 complementary metrics, namely: the repeatability of position residuals, the power-spectrum of position residuals, the estimated time-correlation properties, the corresponding velocity uncertainties, and the spatial correlation of the residuals. We show that NTAOL deformations cause a latitude-dependent bias in white noise plus power-law model parameter estimates. This bias is significantly mitigated when correcting for NTAOL deformation, which reduces velocity uncertainties at high latitudes by $70 \%$. Therefore, removing NTAOL deformation before the statistical analysis of VLM time series might help to detect subtle VLM signals in these areas. Our spatial correlation analysis also reveals a seasonality in the spatial correlation of the residuals, which is reduced after removing NTAOL deformation, confirming that NTAOL is a clear source of common-mode errors in GNSS VLM time series.
\end{abstract}

\title{
Plain Language Summary
}

Monitoring vertical land motions (VLMs) at the level of $0.1 \mathrm{~mm} / \mathrm{yr}$ remains one of the most challenging scientific applications of global navigation satellite systems (GNSS). Such small rates of change can result from climatic and tectonic phenomena, and their detection is important to the prediction of coastal sea-level change and the understanding of deformation processes acting within tectonic plates. In this paper, we investigate to what extent accounting for the deformation of the Earth's crust due to changes in the distribution of the atmospheric and the oceanic pressure helps to detect small vertical ground deformation. By analyzing the data from over 10,000 globally distributed GNSS stations, we show that accounting for such atmospheric and oceanic deformation can reduce by $70 \%$ the uncertainty on the vertical velocity of GNSS stations at high latitudes, which could, for instance, improve sea-level change monitoring in these areas.

\section{Introduction}

Analyzing vertical land motion (VLM) time series estimated from global navigation satellite systems (GNSS) provides key information about the deformation of the Earth. In particular, estimating GNSS station long-term vertical velocities and their uncertainties is a crucial step, aiming at giving reliable inputs for the understanding of inter- and intraplate tectonic deformation (Elliott et al., 2016; Kreemer et al., 2020), glacial isostatic adjustment (Nocquet et al., 2005; Schumacher et al., 2018; Husson et al., 2018), and coastal sea-level change (Wöppelmann et al., 2007; Pfeffer \& Allemand, 2016; Ballu et al., 2019).

Measuring vertical deformations at velocities of a few $0.1 \mathrm{~mm} / \mathrm{yr}$ is one of the most challenging scientific applications of GNSS, required to monitor, for instance, slow intraplate (Masson et al., 2019; Craig \& Calais, 2014) and climate change-related Earth deformations (Wöppelmann \& Marcos, 2016). This metrological goal could be met by improving the quality of GNSS positioning, the stability of reference frames, and the statistical modeling of geodetic time series. 
To estimate long-term velocities, it is customary to decompose the position time series as the sum of two parts: a deterministic component and a stochastic variability (Bos et al., 2020). In practice, the first is described by a trajectory model, whereas the latter is described by a stochastic model. The trajectory model typically consists of known parametric functions - trends, offsets, periodic oscillations, and episodic nonlinear motions - depending on unknown deterministic parameters (Bevis \& Brown, 2014). The stochastic model consists of a set of stochastic processes with known covariance functions depending on unknown stochastic parameters - or variance components - (Bos et al., 2020).

Since the late 1990s, numerous studies demonstrated that the stochastic variability of GNSS position time series, often referred to as noise, can be approximated by a linear combination of white noise (WN) and power-law (PL) processes (Zhang et al., 1997; Mao et al., 1999; Calais, 1999; Williams et al., 2004; Langbein, 2008; Santamaría-Gómez et al., 2011). Power-law processes are stochastic processes characterized by their power spectra $P(f)$, which follows a power-law function of the time frequency $f$, such that

$$
P(f) \approx P_{0}\left(\frac{f}{f_{0}}\right)^{\kappa},
$$

where both $P_{0}$ and $f_{0}$ are normalization constants, and $\kappa$ is the so-called spectral index (Agnew, 1992).

The spectral index $\kappa$ is a scalar identifying the nature of the power-law correlation. Its reported value usually lies within $[-3,1]$ in Earth sciences, and within $[-2,0]$ in GNSS time series analysis. Some power-law processes with integer values of $\kappa$ are known as white - that is, uncorrelated - noise $(\kappa=0)$, flicker noise $(\kappa=-1)$, and random walk noise $(\kappa=-2)$. The power-law processes with $\kappa<0$ are time-correlated. For $\kappa \leq-1$, the power-law process is also non-stationary, and the variance of the process diverges with time.

Accounting for the power-law behavior of the stochastic variability in GNSS position time series is essential for long-term velocity estimation to obtain realistic estimation of the uncertainties (Williams, 2003a; Santamaría-Gómez et al., 2011). Although considered in many geodetic studies (Agnew, 1992; Langbein, 2004; Van Camp et al., 2005), the presence of power-law processes in GNSS position time series remains largely unexplained (Santamaría-Gómez \& Ray, 2021). Given that these power-law processes are the primary source of uncertainty for velocity estimates, it is crucial to identify their origin(s) and to reduce their influence on the position time series.

The stochastic variability observed in position time series is also spatially correlated (Wdowinski et al., 1997). In global solutions, significant spatial correlations are detected between stations up to a few thousand kilometers apart (Williams et al., 2004; Amiri-Simkooei, 2009, 2013; Amiri-Simkooei et al., 2017; Benoist et al., 2020). The presence of large-scale spatial correlations indicates that the stochastic variability cannot be fully attributed to station-specific errors, and that it probably results from a combination of large scale positioning errors and non-modelled geophysical or climatic processes (Amiri-Simkooei et al., 2017; Kreemer \& Blewitt, 2021).

Possible candidates for explaining large-scale structures in the stochastic variability are the non-tidal loading (NTL) deformations, that is, the elastic response of the solid Earth to changes in the distribution of atmospheric, oceanic, and hydrological loads. Following the International Earth Rotation and Reference System Service (IERS) conventions (Petit \& Luzum, 2010), NTL corrections are usually not applied during the estimation of position time series, therefore NTL signals remain in VLMs time series products. 
Over the last two decades, numerous studies demonstrated that NTL corrections derived from numerical climatic load and elastic Earth models help reduce the stochastic variability in GNSS VLM time series, whether applied at the GNSS observation level - that is, prior to the computation of daily positions - (Gegout et al., 2010; Dach et al., 2011; Tregoning \& van Dam, 2005; Männel et al., 2019) or at the solution level - that is, after computing daily positions - (Van Dam et al., 1994, 2001; Williams \& Penna, 2011; Van Dam et al., 2012; Martens et al., 2020; Klos et al., 2021). Regarding VLMs, the differences between the two correction strategies seem negligible (Tregoning \& Watson, 2009).

As numerical climatic load models perform better at retrieving atmospheric and oceanic than hydrological loads (Mémin et al., 2020), in this work, we focus on assessing the effect of non-tidal atmospheric and oceanic loading (NTAOL) deformations on the stochastic properties of GNSS VLM time series. NTAOL deformations introduce both periodic and aperiodic deformation in VLM time series. Because annual and semi-annual signals are always accounted for in the trajectory model, for time series longer than a few years, the periodic (i.e., seasonal) part of NTAOL deformations has a negligible influence on velocity uncertainties (Blewitt \& Lavallée, 2002). This study, therefore, focuses on the impact of aperiodic NTAOL deformations.

Usually, the influence of NTAOL on the stochastic properties of GNSS time series is investigated through the study of change in root mean squared errors (RMSEs) (Tregoning \& van Dam, 2005; Martens et al., 2020), sometimes at different frequency bands (Mémin et al., 2020; Klos et al., 2021). In this work, to further study possible changes in timecorrelation and try to identify the origin of the stochastic variability in GNSS time series, we investigate the influence of correcting for NTAOL deformation (at the solution level) on 5 complementary metrics, namely: the repeatability of position residuals, the power spectrum of position residuals, their time-correlation properties, the corresponding velocity uncertainties, and the spatial correlation of position residuals.

To describe the stochastic variability and the influence of aperiodic NTAOL deformations, we investigate each of these metrics using the position time series of over 10,000 globally distributed GNSS stations. Considering as many stations allows describing with an unprecedented resolution the impact of NTAOL deformations on the spatial correlation of GNSS VLM time series. Besides, systematically analyzing the impact of NTAOL deformations on the stochastic properties of each station allows us to evidence previously unreported stochastic parameter estimation issues, resulting in recommendations for the estimation of velocity uncertainties from global GNSS VLM time series.

\section{Data}

\subsection{GNSS position time series}

We used the North, East, and Up position time series of a total of 10,151 GNSS stations processed and distributed by the Nevada Geodetic Laboratory at the University of Nevada, Reno (Blewitt et al., 2018). This study focuses on the Up coordinates, however, the North and East coordinates have been used in the preprocessing for the detection of discontinuities. NGL's position time series have been computed using the Jet Propulsion Laboratory's (JPL) GipsyX 1.0 software (Bertiger et al., 2020) based on singlestation precise point positioning (PPP) with carrier phase ambiguity resolution (Zumberge et al., 1997). The satellite orbit and clock used for the PPP processing are JPL's Repro 3.0 products. Though we employ the term GNSS for the sake of generality, NGL's processing only exploited observations from the Global Positioning System (GPS). The final position time series are expressed in the IGS14 reference frame. Incremental zenith wet delays are estimated on top of a priori hydrostatic and wet zenith tropospheric delays interpolated from the VMF1 grids (Boehm et al., 2006). Both hydrostatic and wet zenith delays are mapped to the observation elevations using the Vienna Mapping Func- 
tion (VMF1). For the ionospheric delays, the first-order effects are removed thanks to the use of the ionosphere-free L1/L2 combination and second-order effects are corrected using ionospheric TEC maps together with a model of Earth's magnetic field. For more details about NGL's processing strategy, we refer to http://geodesy.unr.edu and Kreemer et al. (2020) or Martens et al. (2020).

\subsection{Loading deformation time series}

To remove NTAOL deformations from GNSS position time series, we used the nontidal atmospheric loading (NTAL) and non-tidal oceanic loading (NTOL) deformation time series computed by the Earth System Modelling group of the German Research Center for Geosciences at Potsdam (ESMGFZ) (Dill \& Dobslaw, 2013). The vertical deformations caused by NTAL are calculated by the ESMGFZ using the 3-hourly atmospheric surface pressure from the European Center for Medium-Range Weather Forecast (ECMWF). The vertical deformations caused by NTOL are calculated using the 3-hourly ocean bottom pressure from the Max-Planck-Institute Meteorology Ocean Model (MPIOM). For both load types, vertical displacements are computed using patched Green's functions computed from the ak135 elastic Earth model (Kennett et al., 1995). For more details about the ESMGFZ processing strategy, we refer to Dill and Dobslaw (2013).

NGL's position time series being expressed in the IGS14 reference frame, we use the deformation time series expressed in the center of Earth's figure frame (CF) (Blewitt, 2003). Because of the higher sampling rate of ESMGFZ's NTAOL deformation time series, we down-sample ESMGFZ's time series at NGL's time series epochs.

\section{Time correlation analysis}

\subsection{Position selection}

For each station, to remove possibly unreliable position estimates, epochs showing a formal error above $5 \mathrm{~mm}$ on any of the three coordinates were ignored. Moreover, to eliminate large outliers, the raw position estimates were compared to a running monthly median. Any epoch with a position showing a deviation from the median exceeding 5 times the median absolute deviation, on any of the three coordinates, was discarded (Klos et al., 2015).

Only position estimates prior to January 2018 were considered in this study. Also, as we focus on time correlation, we only used stations presenting time series with over 1090 daily estimates, that is, more than about 3 years of continuous observations. The spans of the considered time series range from 3 to over 20 years, with a median of 8 years. The distribution of the GNSS sites with their number of data points are presented in Figure S1, provided in the Supporting Information.

\subsection{Trajectory model}

Noting $\mathbf{y}$ the $m \times 1$ observation vector (i.e., a GNSS VLM time series), the trajectory model describes the expectation $\mathrm{E}\{$.$\} of \mathbf{y}$. To simplify the processing of thousands of stations, this study only uses linear trajectory models accounting for a linear trend, periodic signals, remaining outliers, offsets, and trend discontinuities. The trajectory model can be expressed as

$$
\mathrm{E}\{\mathbf{y}\}=\mathbf{A x}
$$

where $\mathbf{A}$ is the $m \times n$ design matrix, that is, the Jacobian of the trajectory model, and $\mathbf{x}$ is the unknown $n \times 1$ deterministic parameter vector. 
The periodic signals accounted for in this trajectory model include the most commonly observed ones in GNSS time series (Ray et al., 2008; Amiri-Simkooei, 2013), namely, the annual signal with a period of 365.25 days and its first 2 harmonics, the draconitic signal with a period of 351.40 days and its first 7 harmonics, and the 3 fortnightly signals with periods of $13.62,14.17$, and 14.76 days.

To model the offsets, all the offset dates indicated in the NGL database have been considered by default. This database includes dates of known equipment changes and possible earthquake-related discontinuities. This database is not necessarily complete for all stations, and additional offsets must be detected to improve the trajectory model. This issue is addressed using an automatic detection of discontinuities presented in section 3.6 .

\subsection{Stochastic model}

The stochastic model describes the co-variance var\{.\} of the $m \times 1$ observation vector $\mathbf{y}$. Under the assumption that the stochastic variability can be approximated by a linear combination of homogeneous white noise - that is, uncorrelated with constant variance - and a power-law process $(\mathrm{WN}+\mathrm{PL})$, the stochastic model reads

$$
\operatorname{var}\{\mathbf{y}\}=\mathbf{Q}_{\mathbf{y}}=\sigma_{h w}^{2} \mathbf{I}+\sigma_{p l}^{2} \mathbf{Q}_{\kappa} .
$$

where $\sigma_{h w}^{2}$ is the unknown white noise amplitude, $\mathbf{I}$ is the $m \times m$ identity matrix, $\sigma_{p l}^{2}$ is the unknown power-law process amplitude, $\kappa$ is the unknown spectral index, and $\mathbf{Q}_{\kappa}$ is the $m \times m$ covariance matrix associated to a power-law process of spectral index $\kappa$ (Williams, 2003a).

\subsection{Variance component estimation}

Estimating unknown parameters of the stochastic model can be done using Variance Component Estimation (VCE) methods. In this study, we use the Least-Squares Variance Component Estimation (LS-VCE) method to estimate the amplitude of each process, namely $\sigma_{h w}^{2}$ and $\sigma_{p l}^{2}$. Introduced by Teunissen (1988) and further developed by Teunissen and Amiri-Simkooei (2008) and Amiri-Simkooei (2007), the LS-VCE method is an unbiased and minimum-variance alternative to the more commonly used Maximum Likelihood Estimation (MLE) method (Zhang et al., 1997; Williams, 2008; Bos et al., 2008; Langbein, 2017) and has already been used in its univariate and multivariate forms for GNSS noise analyses (Amiri-Simkooei et al., 2007; Amiri-Simkooei, 2009; Amiri-Simkooei et al., 2017).

Because the LS-VCE method is unconstrained, it can occasionally return negative estimates, which makes no physical sense for stochastic process amplitudes. When encountering negative variance estimates, we systematically applied the Non-Negative LSVCE method (NNLS-VCE) introduced in Amiri-Simkooei (2016) to obtain non-negative process amplitudes. Though mentioned explicitly in this paper, the non-negativity constraint is the norm, since the nonlinear optimization methods used in most software simply do not explore negative solutions (Williams, 2008; Bos et al., 2008; Langbein, 2017).

In their linear forms, both the LS-VCE and the NNLS-VCE methods do not allow estimating the unknown spectral index $\kappa$. Hence, to assess both the process amplitudes $\hat{\sigma}_{h w}^{2}$ and $\hat{\sigma}_{p l}^{2}$, and the spectral index $\hat{\kappa}$, we systematically tested for each time series 30 stochastic models with discrete values of $\kappa$ ranging from -1.8 to -0.3 with a step of +0.05 . The most likely $\hat{\kappa}$ and the corresponding process amplitudes, were chosen as those maximizing the restricted likelihood defined in Koch (1986). 
When VLM is expressed in millimeters $(\mathrm{mm})$, the power-law amplitude estimate $\hat{\sigma}_{p l}$ is expressed in $\left(\mathrm{mm} \mathrm{yr}^{\kappa / 4}\right)$ if the scaling of Williams (2003a) is used. Therefore, two $\sigma_{p l}$ obtained with different spectral indices are not comparable. To overcome this issue, we use a modified standard deviation, noted $\hat{\sigma}_{p l}^{\prime}$, expressed in $\mathrm{mm}$ and representing the square root of the expected empirical variance of a power-law process over 8 years, which is the median cumulative span of the considered VLM time series.

Noting $\mathbf{r}$ a random vector such that $\mathbf{r} \sim \mathcal{N}\left(\mathbf{0}, \hat{\sigma}_{p l}^{2} \mathbf{Q}_{\kappa}\right)$, the amplitude $\hat{\sigma}_{p l}^{\prime}$ is defined as

$$
\hat{\sigma}_{p l}^{\prime}=\sqrt{\mathrm{E}\left\{\frac{1}{m^{\prime}} \sum_{i=1}^{m^{\prime}}\left(r_{i}-\bar{r}\right)^{2}\right\}}
$$

where $r_{i}$ is an element of the vector $\mathbf{r}, m^{\prime}$ is the number of observations for an 8-year long time series, and $\bar{r}$ is the arithmetic mean of the $r_{i}$.

As power-law processes with $\kappa \leq-1$ are non-stationary, their modified standard deviations $\hat{\sigma}_{p l}^{\prime}$ increase with $m^{\prime}$. Therefore, to allow comparisons between $\hat{\sigma}_{p l}^{\prime}$ values, $m^{\prime}$ is kept fixed for all time series.

One can show that $\hat{\sigma}_{p l}^{\prime}$ can be expressed as

$$
\hat{\sigma}_{p l}^{\prime}=\hat{\sigma}_{p l} \sqrt{\frac{1}{m^{\prime}} \operatorname{tr}\left\{\mathbf{Q}_{\kappa}^{\prime}\right\}-\frac{1}{m^{\prime 2}} \mathbf{u}^{T} \mathbf{Q}_{\kappa}^{\prime} \mathbf{u}}
$$

with $\mathbf{u}$ a $m^{\prime} \times 1$ vector defined as $\mathbf{u}^{T}=\left[\begin{array}{llll}1 & 1 & \cdots & 1\end{array}\right]$ and $\mathbf{Q}_{\kappa}^{\prime}$ the covariance matrix of a power-law process with spectral index $\kappa$ and length $m^{\prime}$.

\subsection{Residual estimation}

Part of the investigations presented in this work are based on the analysis of the residual VLM time series. Residual time series are computed as the difference between the observations and the trajectory model estimated by weighted least-squares (Teunissen, 2000a). In particular, the residual vector $\hat{\mathbf{e}}$ is computed from the observation vector $\mathbf{y}$ by

$$
\hat{\mathbf{e}}=\mathbf{P}_{\mathrm{A}}^{\perp} \mathbf{y}
$$

in which the $m \times m$ matrix $\mathbf{P}_{\mathbf{A}}^{\perp}$ is the weighted least-squares orthogonal projector defined by

$$
\mathbf{P}_{\mathbf{A}}^{\perp}=\mathbf{I}-\mathbf{A}\left(\mathbf{A}^{T} \mathbf{W A}\right)^{-1} \mathbf{A}^{T} \mathbf{W} .
$$

where $\mathbf{W}$ denotes the $m \times m$ weight matrix. Hereafter, unless specified otherwise, the weight matrix $\mathbf{W}$ is taken as the inverse of the covariance matrix of the observations: $\mathbf{W}=\mathbf{Q}_{\mathbf{y}}^{-1}$.

\subsection{Trajectory model improvement}

As undetected offsets can bias stochastic parameter estimates (Williams, 2003b), it is necessary to identify possible additional offsets to the NGL database and to include them in the trajectory models. In practice, the offset detection is often done manually, since experimented operators tend to perform better than most algorithms (Gazeaux et 
al., 2013). However, when considering thousands of time series, an automatic detection is necessary.

Amiri-Simkooei et al. (2019) recently showed that one can improve the automatic detection of offsets by accounting for the time-correlated noise, and by analyzing the North $(n)$, East $(e)$, and Up $(h)$ coordinates simultaneously. The multivariate LS-VCE used in Amiri-Simkooei et al. (2019) assumes constant $\sigma_{h w}^{2} / \sigma_{p l}^{2}$ ratios for all coordinates, which might be a risky hypothesis. Here, we relax this hypothesis and adapt the method of AmiriSimkooei et al. (2019) to allow process amplitudes to have different amplitude ratios for each coordinate. We then check for discontinuities, including offsets, outliers, and velocity changes.

The detection method is derived from the Detection Identification Adaptation (DIA) procedure introduced by Baarda (1968); Teunissen (2000b). Applied to the detection of offsets, outliers, or velocity changes, the DIA procedure consists in testing a null hypothesis $H_{0}: \mathrm{E}\{\mathbf{y}\}=\mathbf{A} \mathbf{x}$ against an alternative hypothesis $H_{a}: \mathrm{E}\{\mathbf{y}\}=\mathbf{A} \mathbf{x}+\mathbf{c}_{a}\left(t_{k}\right) x_{a}$, in which $\mathbf{c}_{a}\left(t_{k}\right)$ is the known $m \times 1$ Jacobian vector of a discontinuity of type $a$ (either an offset, an outlier or a velocity change) at time $t_{k}$ with an unknown amplitude $x_{a}$. According to Teunissen (2000b), accepting or rejecting $H_{0}$ depends on the value of a $T$-statistic defined by

$$
T_{a}\left(t_{k}\right)=\frac{\left(\mathbf{c}_{a}^{T}\left(t_{k}\right) \mathbf{Q}_{\mathbf{y}}^{-1} \hat{\mathbf{e}}\right)^{2}}{\mathbf{c}_{a}^{T}\left(t_{k}\right) \mathbf{Q}_{\mathbf{y}}^{-1} \mathbf{P}_{\mathbf{A}}^{\perp} \mathbf{c}_{a}\left(t_{k}\right)}
$$

Under $H_{0}$, the random variable $T_{a}\left(t_{k}\right)$ follows a central chi-squared distribution with 1 degree of freedom: $T_{a}\left(t_{k}\right) \sim \chi^{2}(1,0)$. Hence, for a given confidence level $\alpha$, if $T_{a}\left(t_{k}\right)>$ $\chi_{\alpha}^{2}(1,0)$, the null hypothesis can be rejected and $\mathbf{c}_{a}$ can be added to the columns of the design matrix $\mathbf{A}$.

To combine the information of all coordinates, we define the power $P_{a}\left(t_{k}\right)$ of a discontinuity $\mathbf{c}_{a}\left(t_{k}\right)$ at time $t_{k}$ as the sum of the $T$-statistics estimated on each coordinate, that is

$$
P_{a}\left(t_{k}\right)=\sum_{i \in\{n, e, h\}} T_{a}^{(i)}\left(t_{k}\right),
$$

where the residual vector $\hat{\mathbf{e}}_{(i)}$, the covariance matrix $\mathbf{Q}_{\mathbf{y}_{(i)}}$, and the orthogonal projector $\mathbf{P}_{\mathbf{A}_{(i)}}^{\perp}$ are specific to each coordinate $(i)$.

Assuming that the coordinates are uncorrelated (Amiri-Simkooei, 2009; Benoist et al., 2020), under $H_{0}$, the power $P_{a}\left(t_{k}\right)$ follows a central chi-squared distribution with 3 degrees of freedom, that is $P_{a}\left(t_{k}\right) \sim \chi^{2}(3,0)$.

The chi-squared distribution of $T_{a}\left(t_{k}\right)$ and $P_{a}\left(t_{k}\right)$ is based on the assumption that the covariance matrices $\mathbf{Q}_{\mathbf{y}(i)}$ are known. However, the two variance components $\sigma_{w}^{2}$ and $\sigma_{p l}^{2}$ are unknown and must be estimated. In such a case, the exact distribution of $T_{a}\left(t_{k}\right)$ becomes intractable. Nonetheless, the chi-squared distribution remains a good approximation, as the redundancy of the trajectory model $m-n$ is large (Amiri-Simkooei et al., 2019).

To find a candidate for the alternative hypothesis $\mathbf{c}_{a}\left(t_{k}\right)$, offsets $\mathbf{c}_{o}\left(t_{k}\right)$, outliers $\mathbf{c}_{t}\left(t_{k}\right)$, and velocity changes $\mathbf{c}_{v}\left(t_{k}\right)$ were systematically tested for each epoch $t_{k}$. The most-likely discontinuity date $\hat{t}_{k}$ and type $\hat{a}$, were chosen as

$$
\hat{a}, \hat{t}_{k}=\underset{a, t_{k}}{\arg \max } P_{a}\left(t_{k}\right) .
$$


When the power of the most likely alternative $P_{\hat{a}}\left(\hat{t}_{k}\right)$ exceeded a given threshold $P_{\hat{a}}\left(\hat{t}_{k}\right)>25$, the discontinuity $\mathbf{c}_{\hat{a}}\left(\hat{t}_{k}\right)$ was added to the trajectory model. The threshold value 25 is arbitrarily chosen and corresponds to a confidence level $\alpha>0.9999$ under the $\chi^{2}(3,0)$ hypothesis. This detection procedure was repeated until no significant discontinuities were found anymore. At each iteration, the variance components of the stochastic model were (re)estimated for all coordinates. To reduce the computational burden, and for this detection step only, we used a fixed spectral index $\kappa=-0.80$ and the NNLS-VCE method by default.

In the end, an average of 2.49 offsets, 0.67 outliers, and 0.97 velocity changes were added to the trajectory model of each station. To compensate for the linearity of the trajectory model, stations showing nonlinear behaviors such as post-seismic deformation present more offsets and velocity changes than the others. But the median number discontinuity per station is actually 1.0 for the offsets and 0.0 for both the outliers and the velocity changes. The imperfect nature of this detection procedure certainly results in an overparameterization of the trajectory model of some stations. However, considering that we focus on large scale patterns obtained from a large number of independently processed stations, a possible over-parameterization of a few trajectory models is unlikely to affect the results discussed in section 5 .

\section{Spatial correlation analysis}

Williams et al. (2004) computed the variation of the cross-correlation between pairs of residual time series with the station's separation distance. Amiri-Simkooei (2009); AmiriSimkooei et al. (2017) did a similar analysis but used a particular metric to take time correlation into account. However, this metric, based on the multivariate LS-VCE (AmiriSimkooei, 2009), assumes an identical white noise to power-law amplitude ratio and an identical spectral index for all the time series. Benoist et al. (2020) assumed a secondorder stationary spatial distribution of residuals and investigated the spatial correlation using variograms (Wackernagel, 2013).

In these studies, the spatial correlation coefficients were systematically estimated using all observations over a span of a few years. In results, the estimated coefficient was an average over the considered span. In practice, for short time scales, let us say a few weeks, one would expect the spatial correlation structure to show a time-variable behavior, especially if position residuals are linked to climate-related mass redistribution.

Hence, to investigate the time dependence of the spatial correlation, we computed the Pearson correlation coefficients between pairs of residual time series over running windows of 30 days. We then averaged these pairwise correlation coefficients for 200 independent classes of separation distances, ranging from [0, 100] to [19900, 20000] km. Correlation coefficients obtained from 30-day windows are less precise than those based on several years. However, given the number of stations analyzed in this study, the final spatial correlation estimates result from an average of over a few hundred thousands pairs in each distance class, making them robust and interpretable nevertheless.

\section{Influence of aperiodic NTAOL deformations}

\subsection{Repeatability}

To measure the change in repeatability resulting from the correction of either NTAL or NTOL deformations, we analyze RMSE reductions. In this part, residuals are computed using the unweighted least-squares adjustment, that is, using $\mathbf{W}=\mathbf{I}$ in Equation 7 . As the trajectory model accounts for annual and semi-annual signals, the changes in RMSE do not reflect changes of the seasonal variations in the series, as those are not present in the residuals. 

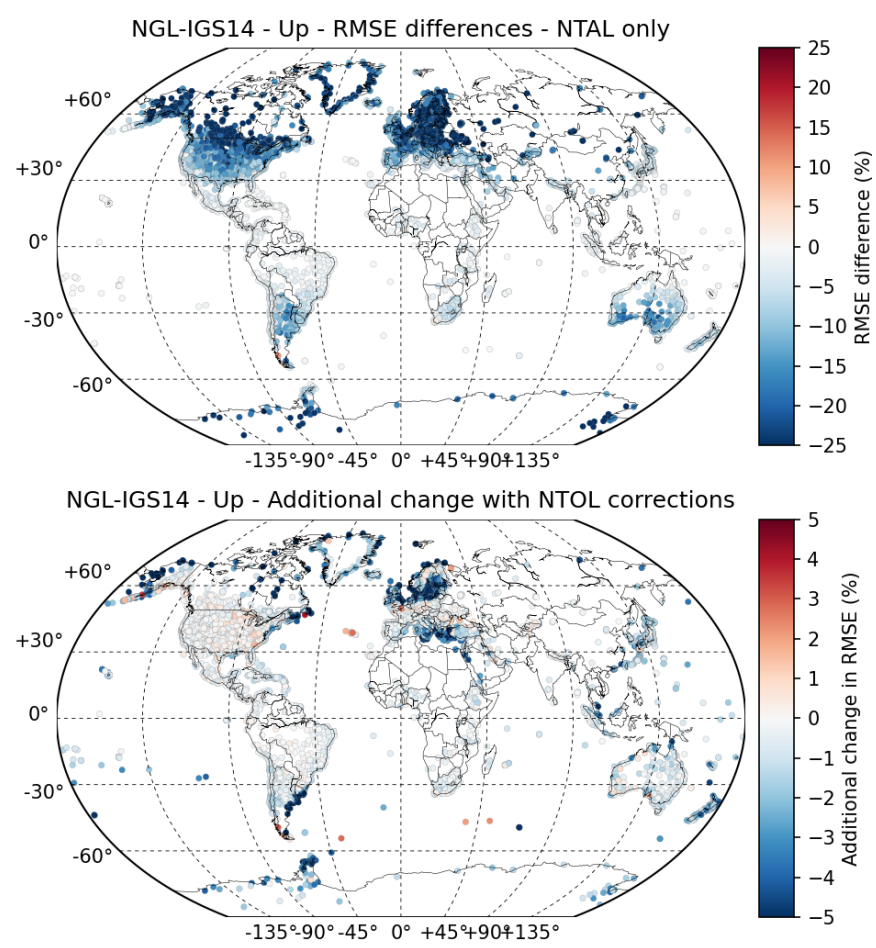

Figure 1. Global distribution of change in RMSE after removing ESMGFZ's NTAL deformation predictions only (top), and additional change in RMSE after also removing NTOL deformation predictions (bottom).

The global distribution of the change in RMSE obtained after removing NTAL deformations, and the additional change resulting from also removing NTOL deformations, are presented in Figure 1. NTAL corrections result in an RMSE reduction for $97.5 \%$ of the stations. The global-average change in RMSE is $-11.4 \%$, but the differences are more pronounced at latitude over $\pm 45.0^{\circ}$ than near the equator, where the atmospheric pressure is less variable (Van Dam \& Wahr, 1987). NTOL corrections result in an additional RMSE reduction for $72.8 \%$ of the stations. Though lower by a factor 5 , the impact of NTOL, like that of NTAL, is higher near the poles, but logically confined to coastal areas. With an overall reduction of about $30 \%$ at high latitudes and about $0 \%$ at the equator, the high latitude reduction observed here is about $10 \%$ better than that reported in Fig. 7 in Mémin et al. (2020), probably because their dataset mostly contains coastal GNSS stations.

Our results show that the correction of either NTAL or NTOL deformations results in a quasi-systematic scatter reduction of the aperiodic VLM residual time series. Hence, though this dataset aggregates observation from GNSS stations with variable geodetic quality, the recently reprocessed NGL's position time series are, nonetheless, of particular interest for NTL deformation studies.

Because removing NTAL and NTOL deformations results in RMSE reduction for the wide majority of stations, in the following, we focus on their combined effect, that is, the impact of the non-tidal atmospheric and oceanic loading (NTAOL $=$ NTAL + NTOL) on the spectral, temporal, and spatial properties of the stochastic variability in VLM time series. 


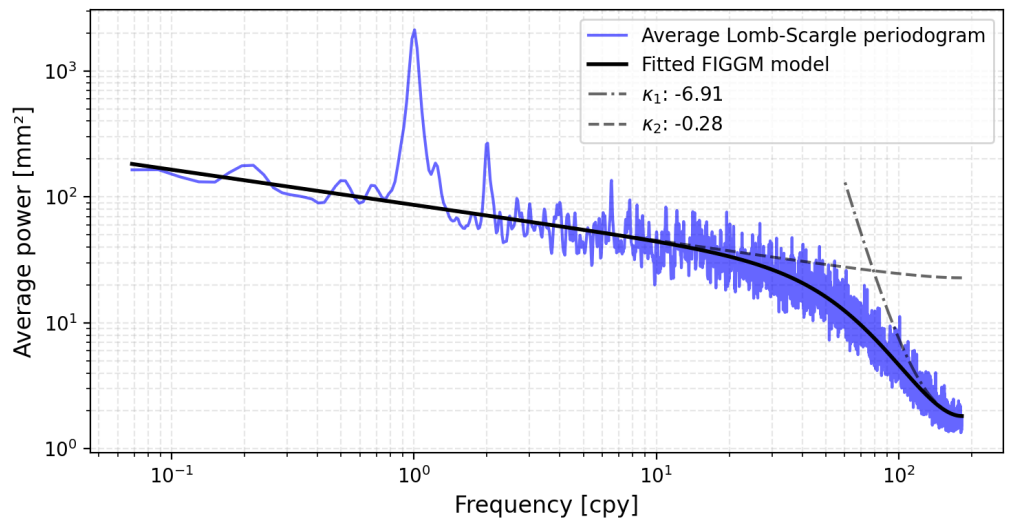

Figure 2. Average Lomb-Scargle periodogram of the ESMGFZ's vertical NTAOL deformation time series (blue solid line). The NTAOL deformation time series have the same sampling and gaps as the GNSS time series. The average power is computed using only time series with a span longer than the considered period. The average power spectrum is approximated by a Fractionally Integrated Generalized Gauss-Markov model (FIGGM, black solid line). The dash dotted black line represents the spectral index $\kappa_{1}=-6.91$ at high frequencies. The dashed black line represents the spectral index $\kappa_{2}=-0.28$ at low frequencies.

\subsection{Average power spectrum}

The improved repeatability observed in the previous section does not indicate whether NTAOL deformations are time-correlated. One way to investigate this effect is to analyze the average power spectrum of the NTAOL deformation time series. In Figure 2, we present the average Lomb-Scargle periodogram of the ESMGFZ's vertical NTAOL deformation time series at the GNSS sites.

The energy of the spectrum is mainly concentrated at low frequencies and rapidly decreases at high frequencies. This indicates that NTAOL deformations are time-correlated. However, the shape of the power-spectrum does not resemble that expected from the combination of white noise and power-law processes, as it collapses instead of flattening at high frequencies. More precisely, the average power-spectrum shows two distinct slopes above, and below, 20.0 cycles per year [cpy]. Time series presenting such a behavior can be well described by a fractionally integrated generalized Gauss-Markov (FIGGM) process (Bos et al., 2020).

The power spectrum $P(f)$ of a discrete FIGGM process reads

$$
P(f)=2 \frac{\sigma^{2}}{f_{s}}\left[1+\phi^{2}-2 \phi \cos \left(2 \pi f / f_{s}\right)\right]^{\kappa_{1} / 2} \times\left[2 \sin \left(\pi f / f_{s}\right)\right]^{\kappa_{2}},
$$

in which $\sigma^{2}$ denotes the amplitude of the process, $f_{s}$ denotes the sampling frequency in cpy, $\kappa_{1}$ denotes the spectral index at high frequencies, $\kappa_{2}$ denotes that at low frequencies, and $\phi$ denotes the Gauss-Markov parameter controlling the transition between both.

The estimated low-frequency spectral index of NTAOL deformation is $\hat{\kappa}_{2}=-0.28$ whereas, at high frequencies, $\hat{\kappa}_{1}=-6.91$. The power-spectrum at high frequencies does not closely follow the steep $\hat{\kappa}_{1}$ slope because of the early transition to $\hat{\kappa}_{2}$, due to a small Gauss-Markov parameter $(\hat{\phi}=0.18)$ corresponding to a crossover frequency of 78.8 cpy. 

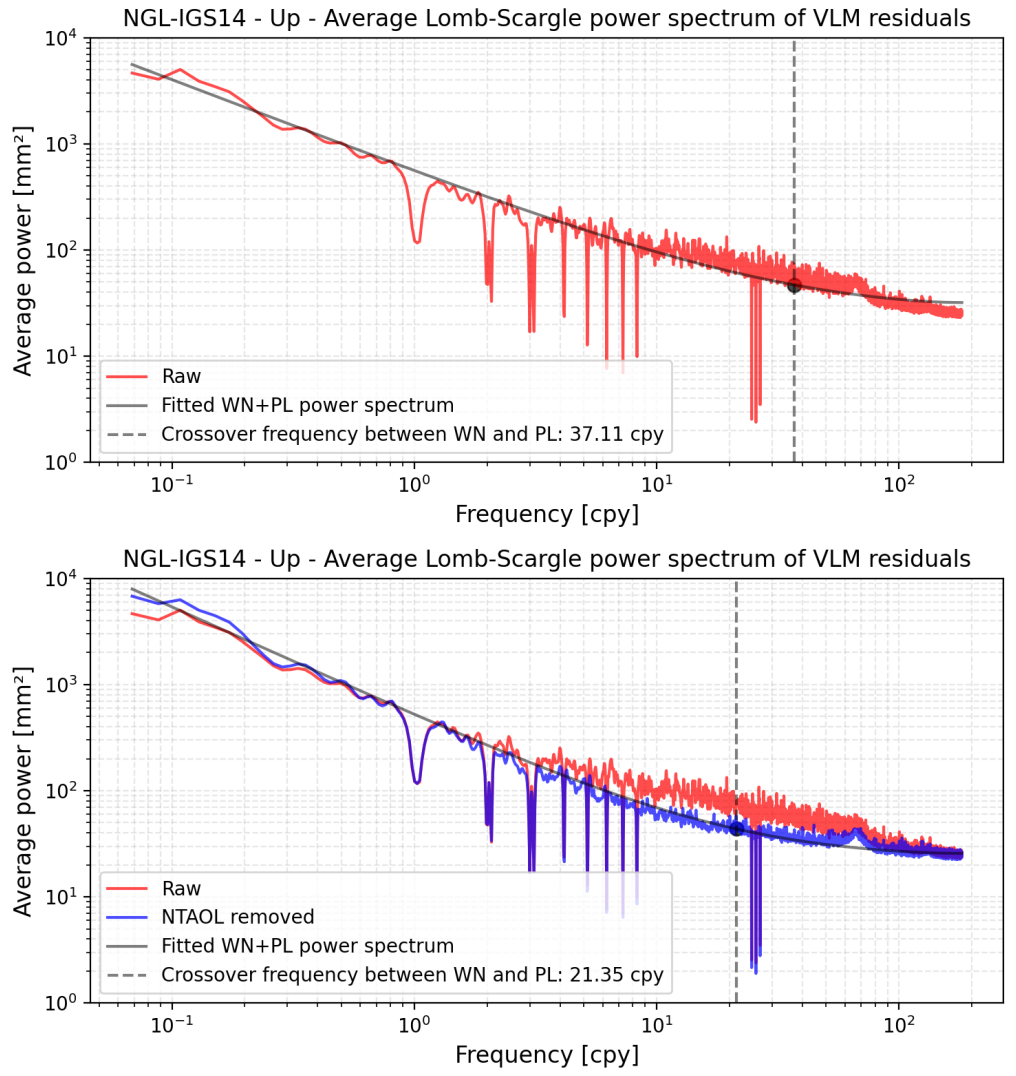

Figure 3. Average Lomb-Scargle periodogram of residual GNSS position time series before (top) and after removing the NTAOL deformations (bottom). The average power is computed using only time series with a span longer than the considered period.

To investigate how the FIGGM nature of NTAOL deformations affects the spectral properties of the stochastic variability in GNSS time series, we computed the average Lomb-Scargle periodogram of VLM residuals before and after removing NTAOL deformations. Unlike in the previous section, hereafter, the VLM residuals are estimated using the inverse of the estimated covariance matrix as the weight matrix, that is, using $\mathbf{W}=\mathbf{Q}_{\mathbf{y}}^{-1}$ in Equation 7. Both periodograms are presented in Figure 3.

In each plot, we observe power drops at the seasonal, draconitic, and fortnightly frequencies accounted for in the trajectory model because the power at these frequencies is absorbed by the deterministic parameters (see Section 3.2). Besides these frequencyspecific drops, both power spectra tend to follow that expected from a WN+PL model, that is, a slope close to -1.00 (flicker noise) at low frequencies and a flattening at high frequencies. Thus, the WN+PL stochastic model used for variance component estimation (section 5.3) seems well-suited to both cases. To illustrate this, in Figure 3, WN+PL power spectra have been adjusted to each average Lomb-Scargle periodogram. The crossover frequency - that is, the frequency where the power resulting from white noise equals that of the power-law process - is also presented in both cases.

Before NTAOL correction, although the WN+PL model approximates the overall shape of the periodogram, it fails to describe the increase in power due to NTAOL deformations between 10 cpy and 70 cpy. On the other hand, after NTAOL correction, there is a much better agreement between the average periodogram and the $\mathrm{WN}+\mathrm{PL}$ 
model. We also observe a more pronounced flattening at high frequencies, which moves the estimated crossover frequency between WN and PL from 37.11 cpy to 21.35 cpy. A wide spectral peak at 66.4 cpy, already reported in Amiri-Simkooei (2013) and Ray et al. (2013), possibly related to the PPP processing (Selle et al., 2014; Amiri-Simkooei et al., 2017), is also more visible after NTAOL corrections.

The difference in power spectra in Figure 3 differs from that in Fig. 8 in Männel et al. (2019), which shows meager differences at high-frequencies and more pronounced ones at low-frequencies. There are two possible reasons for the differences at high-frequencies. The first one is that we use about 65 times more stations, most of them located in Europe and North America. Thus, by averaging, Figure 3 might better reveal NTAOL signals in these areas. Another possibility is the use of the Global Mapping Function (GMF) (Böhm et al., 2006) by Männel et al. (2019), which might result in tropospheric modeling errors that partially compensate for the atmospheric loading signal (Steigenberger et al., 2009) and reduce the influence of NTAOL corrections on their VLMs time series (Martens et al., 2020). The high-frequency flattening of the power-spectrum after NTAOL correction presented in this work (Figure 3 ) seems in better agreement with that presented in Fig. 8 of Tregoning and Watson (2009).

Regarding the low-frequencies, the more significant differences in Männel et al. (2019) are likely due to the correction of hydrology loading, not applied in this work. Also, as the spectral properties of the estimated residuals depend on the estimated stochastic model (through the weight matrix in Equation 7), the change of slope at low-frequencies in Figure 3 is undoubtedly due to the significant changes in spectral indices at mid-latitudes, which we present in the following section.

\subsection{Spatial variability of variance components}

In this section, we present the influence of removing NTAOL deformation on the spatial variability of the estimated white noise amplitudes $\hat{\sigma}_{h w}$, modified power-law amplitudes $\hat{\sigma}_{p l}^{\prime}$, spectral indices $\hat{\kappa}$, and RMSEs.

The global distribution of the estimated variance components using raw VLM time series are presented in Figure 4. That obtained using VLM time series with NTAOL deformations removed are presented in Figure 5. All stochastic parameters show a strong global scale variability, mostly characterized by a latitude dependence, which Figure 6 evidences and compares before and after removal of NTAOL deformation, showing also the RMSE changes in parallel. To improve the legibility of Figure 6, we represent running medians and interquartile ranges over $+10.0^{\circ}$ latitude windows. In the following, the quantitative description of the latitude dependence refers to these running medians and not the individual station estimates.

Before removing NTAOL deformations, the estimated white noise amplitudes reach a maximum of about $4.0 \mathrm{~mm}$ near the equator and are almost always equal to $0.0 \mathrm{~mm}$ for latitudes over $\pm 40.0^{\circ}$, forming an equatorial bulge. After the removal of NTAOL deformations, the spatial variability of the stochastic parameters is strongly modified (Figure 5). Instead of being null everywhere but at low latitudes, the white noise amplitude is now non-zero everywhere. This does not indicate that NTAOL corrections introduce additional white noise in the series, but rather that white noise amplitude estimates based on the uncorrected series were biased low, due to NTAOL deformations partially hiding white noise (see Figure 3). The equatorial bulge in white noise amplitudes remains visible, with a minimum of $2.0 \mathrm{~mm}$ near the poles and a maximum of about $4.0 \mathrm{~mm}$ at the equator.

This bulge was originally pointed out by Williams et al. (2004) but was also more recently observed in IGS station position time series by Klos et al. (2019). Williams et al. (2004) suggested that the origin of this bulge could reside in mis-modeling of the at- 

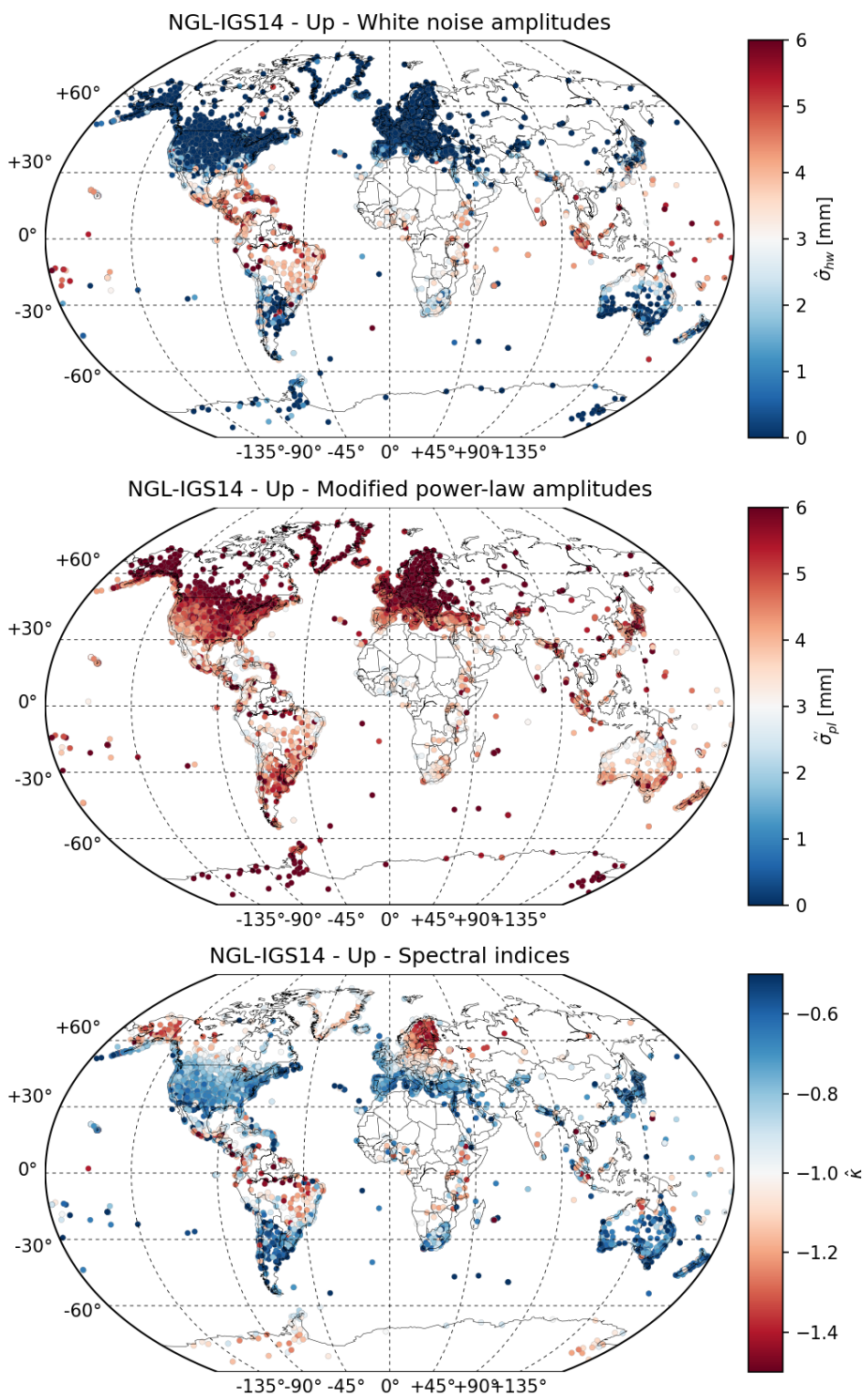

Figure 4. Global distribution of stochastic parameters estimated from raw VLM time series. White noise amplitudes (top). Modified power-law amplitudes (middle). Spectral indices (bottom). 

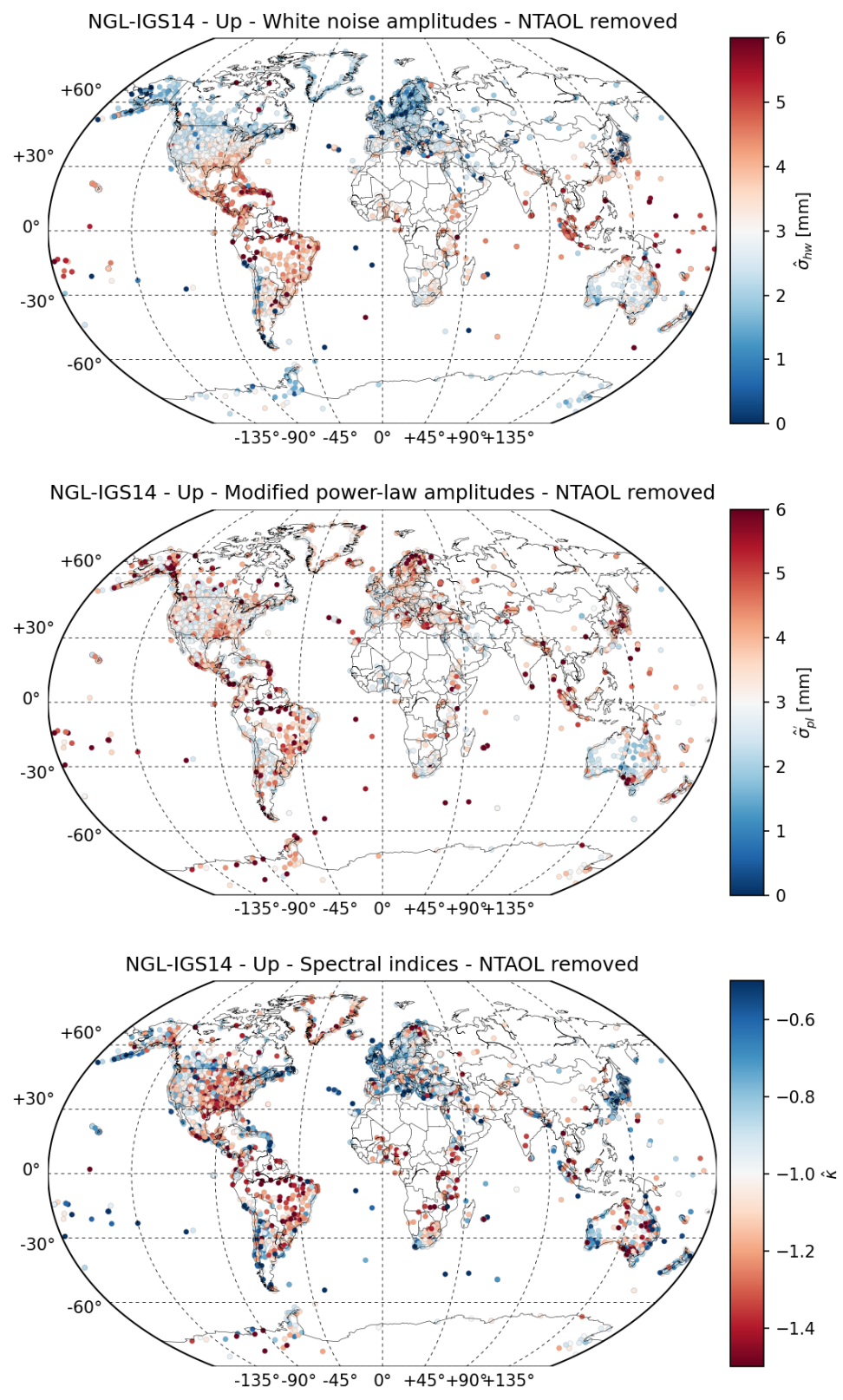

Figure 5. Global distribution of stochastic parameters estimated from VLM time series with NTAOL deformations removed. White noise amplitudes (top). Modified power-law amplitudes (middle). Spectral indices (bottom). 

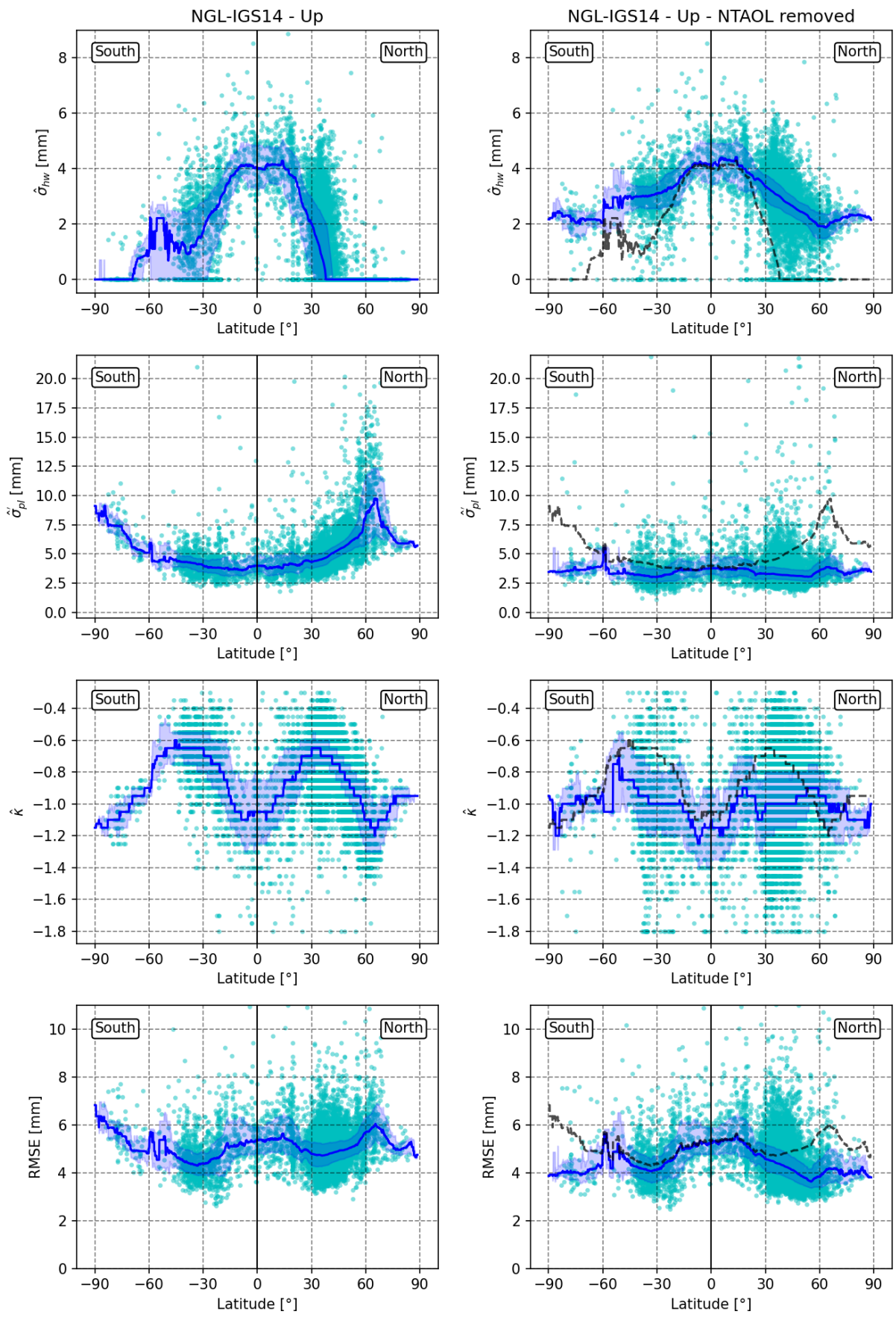

Figure 6. Latitude dependence of white noise amplitudes $\hat{\sigma}_{h w}$ (top), spectral indices $\hat{\kappa}$ (upper middle), power-law amplitudes $\hat{\sigma}_{p l}^{\prime}$ (lower middle), and RMSEs (bottom), in the presence of NTAOL deformations (left) and with NTAOL deformations removed (right). The dots in cyan represent the station-specific estimates. The continuous blue lines represent running medians over $10^{\circ}$ latitude windows. The shaded areas represent the corresponding interquartile ranges. The dashed black lines are the running medians before NTAOL correction, reported in the right plots for comparison with results after NTAOL correction. 
mospheric delays affecting GNSS observations. Although the NGL-IGS14 solution used in this study benefits from recent improvements in the modeling of both tropospheric and second-order ionospheric effects, the bulge remains visible in both datasets. Hence, further investigations are needed to identify its causes and to reduce its amplitude.

Unlike white noise amplitudes, the modified power-law amplitudes before removing NTAOL deformations reach a minimum amplitude of $3.5 \mathrm{~mm}$ near the equator and are maximum at high latitudes, especially near the latitude $+65.0^{\circ}$, where they peak at $10.0 \mathrm{~mm}$. The estimated spectral indices show a bi-modal distribution with a maximum of about -0.65 near $\pm 40.0^{\circ}$ and a minimum of about -1.10 near latitudes $-90.0^{\circ}, 0.0^{\circ}$, and $+65.0^{\circ}$. In other words, the estimated stochastic variability shows longer memory effects near the equator and near the poles than at mid-latitudes. After the removal of NTAOL deformations, the modified power-law amplitudes are dramatically reduced at middle and high latitudes, making their latitude dependence almost disappear. The powerlaw amplitudes now uniformly lie in a narrow range centered around $3.5 \mathrm{~mm}$. For spectral indices, as for the other parameters, the latitude dependence is also affected. After removing NTAOL deformations, the latitudinal medians of the estimated spectral indices no longer show a bi-modal distribution, but a flatter latitude dependence centered on -1.00 , that is, flicker noise. In addition, their interquartile range shows an increase at mid-latitudes, indicating that the spatial distribution is more complex than just a latitude dependence (see Figure 5).

The striking latitude dependence of power-law amplitudes and spectral indices $\hat{\sigma}_{p l}^{\prime}$ visible in Figure 4 was not observed by Williams et al. (2004). This difference is likely due to the processing improvements having occurred over the past 17 years. Such global scale patterns have however been pointed out in Klos et al. (2019, 2020). In Europe, Klos and Bogusz (2017); Gruszczynski et al. (2019) and Klos et al. (2021), suggested that NTL deformations could be the cause of the spatial variability of stochastic parameters observed in the Up component. The observed impact of NTAOL corrections at the global scale from Figures 5 and 6 is consistent with this hypothesis.

Before removing NTAOL deformations, the RMSEs are centered around $5.1 \mathrm{~mm}$ and reach maxima of about $6.0 \mathrm{~mm}$ near the poles and about $5.6 \mathrm{~mm}$ near the equator. After the removal of NTAOL deformations, they now show a slightly subdued latitudinal profile mainly resulting from their significant decrease, from $6.0 \mathrm{~mm}$ to $4.0 \mathrm{~mm}$, at high latitudes, while their values at low latitudes stay unchanged.

Note that, at high latitudes, before removing NTAOL deformations, the amplitude of power-law processes alone exceeds the RMSE of the residuals (Figure 6). As the RMSE accounts for the total effect of white noise plus power-law processes, this indicates that there is a bias in the estimation of the power-law parameters. To illustrate how the estimated stochastic parameters change with NTAOL correction, Figure 7 presents the LombScargle periodogram of the VLM residuals along with the WN+PL power spectrum expected from the estimated stochastic parameters for station ONSA (Onsala, Sweden), both before and after NTAOL correction.

Before NTAOL correction, the estimated power spectrum differs from the LombScargle periodogram of the residuals because of the non-modelled variability at sub-annual periods resulting from the presence of NTAOL deformations (Figure 2). This illustrates that, at high latitudes, where the scatter of the NTAOL deformation is the largest (Tregoning \& van Dam, 2005), the usual WN+PL stochastic model is not appropriate and the associated parameter estimates are not reliable. However, after NTAOL correction, the nonmodelled sub-annual variability is removed, the stochastic variability resembles more that of the $\mathrm{WN}+\mathrm{PL}$ model, which results in more interpretable parameter estimates.

In principle, considering a $\mathrm{WN}+\mathrm{PL}+\mathrm{FIGGM}$ stochastic model instead of a $\mathrm{WN}+\mathrm{PL}$ one could also be a solution to this problem. However, adding a FIGGM process to the 

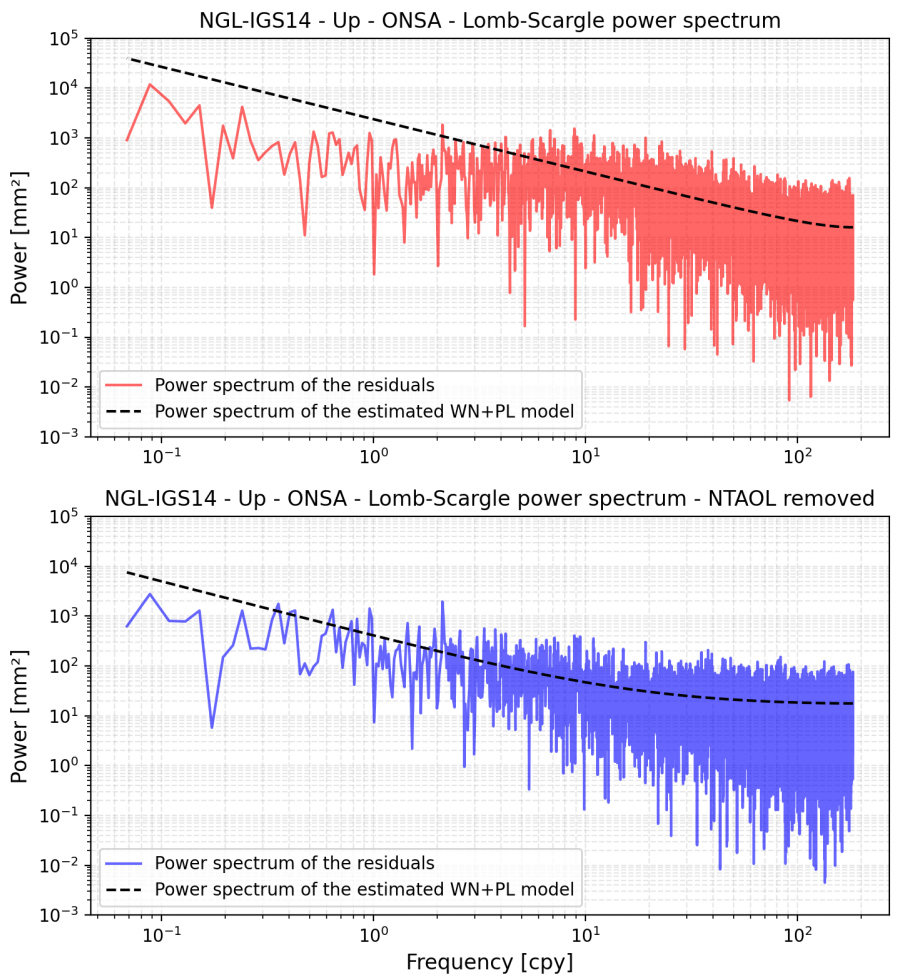

Figure 7. Power spectra of the VLM time series of station ONSA (Onsala, Sweden), before (top) and after (bottom) removing NTAOL deformations. The colored lines are the Lomb-Scargle periodograms of the VLM residuals. The black dashed lines are the $\mathrm{WN}+\mathrm{PL}$ power spectra expected from the estimated stochastic parameters. 
stochastic model would lead to a more complex and nonlinear variance component estimation problem. Correct for the NTAOL deformations before stochastic parameter estimation is a more efficient and pragmatic solution.

Figures 4, 5 and 6 show that all stochastic parameters show a spatial variability, both before and after NTAOL correction. Hence, considering spatially variable stochastic process amplitudes and spectral indices is preferable when analyzing VLM time series. In particular, the assumption of a constant spectral index and of a constant powerlaw to white noise amplitude ratio for all stations, as done in Amiri-Simkooei (2013); AmiriSimkooei et al. (2017), seems sub-optimal in global solutions.

Although we demonstrated that a large part of the spatial variability of stochastic parameters can be attributed to the influence of NTAOL deformations, Figure 5 clearly shows that non-latitudinal patterns remain. This residual variability could be further reduced by improving the accuracy of NTAOL prediction or by accounting also for hydrological loading deformations. Once the strong impact of NTAOL deformation is removed, detecting the influence of the monumentation quality on the stochastic parameters of individual stations in global solutions might become easier (Langbein \& Svarc, 2019).

\subsection{Velocity uncertainties}

Velocity uncertainties depend on the estimated stochastic properties, but also on each station's functional model and span. To isolate the influence of the stochastic properties, for a given stochastic model, we define the minimum 8-year velocity uncertainty, noted $\sigma_{v}^{*}$, as the expected standard deviation of the velocity estimated assuming a continuous 8-year long time series with a trajectory model consisting of a linear trend and the periodic signals presented in section 3.2. $\sigma_{v}^{*}$ is a lower bound estimate because missing values and additional deterministic parameters would increase the velocity uncertainty.

Figure 8 shows the global distribution of $\sigma_{v}^{*}$ obtained from the stochastic parameters estimated before and after NTAOL correction. Figure 9 depicts their latitudinal distributions along with the running medians and the interquartile ranges over $+10.0^{\circ}$ latitude windows. In the Supporting Information, Figure S2 presents an alternative to Figure 8, in which the velocity uncertainties account for the full span of each VLM time series.

Before removing NTAOL deformations $\sigma_{v}^{*}$ is maximum at high latitudes, namely, in Alaska, Canada, around the Baltic Sea, Russia, Antarctica, but also within the Amazon basin. More precisely, the median $\sigma_{v}^{*}$ reaches a maximum of $1.42 \mathrm{~mm} / \mathrm{yr}$ around the latitude $+65.0^{\circ}$, and a minimum of about $0.24 \mathrm{~mm} / \mathrm{yr}$ near $\pm 30^{\circ}$ latitudes.

After NTAOL correction, the latitude dependence of $\sigma_{v}^{*}$ is dramatically reduced. The median $\sigma_{v}^{*}$ are now centered around $0.37 \mathrm{~mm} / \mathrm{yr}$ at all latitudes, with a maximum of $0.55 \mathrm{~mm} / \mathrm{yr}$ near the equator and a minimum around $0.26 \mathrm{~mm} / \mathrm{yr}$ near $\pm 45^{\circ}$ latitudes. The most dramatic reduction of $\sigma_{v}^{*}$ is observed around the latitude $+65.0^{\circ}$, where $\sigma_{v}^{*}$ drops from $1.42 \mathrm{~mm} / \mathrm{yr}$ to $0.43 \mathrm{~mm} / \mathrm{yr}$, that is, a $69.7 \%$ decrease. However, the reduction in uncertainty is not systematic and concerns only $49.6 \%$ of the stations. The other $50.4 \%$ show a moderate increase in $\sigma_{v}^{*}$ (Figure 9 ) because of the variance component estimation bias caused by uncorrected NTAOL deformations, which results in overestimated spectral indices at mid-latitudes (e.g., Figure 6).

The other stations, mostly localized at mid-latitudes, show a moderate increase in uncertainty. An apparent increase in outliers is also observed at mid-latitudes, mainly caused by groups of stations near the northern coasts of the Gulf of Mexico, the south of Brazil, and Central Africa showing both strong RMSEs and low spectral indices. But overall, after NTAOL correction, most stations show more homogeneous $\sigma_{v}^{*}$ estimates 

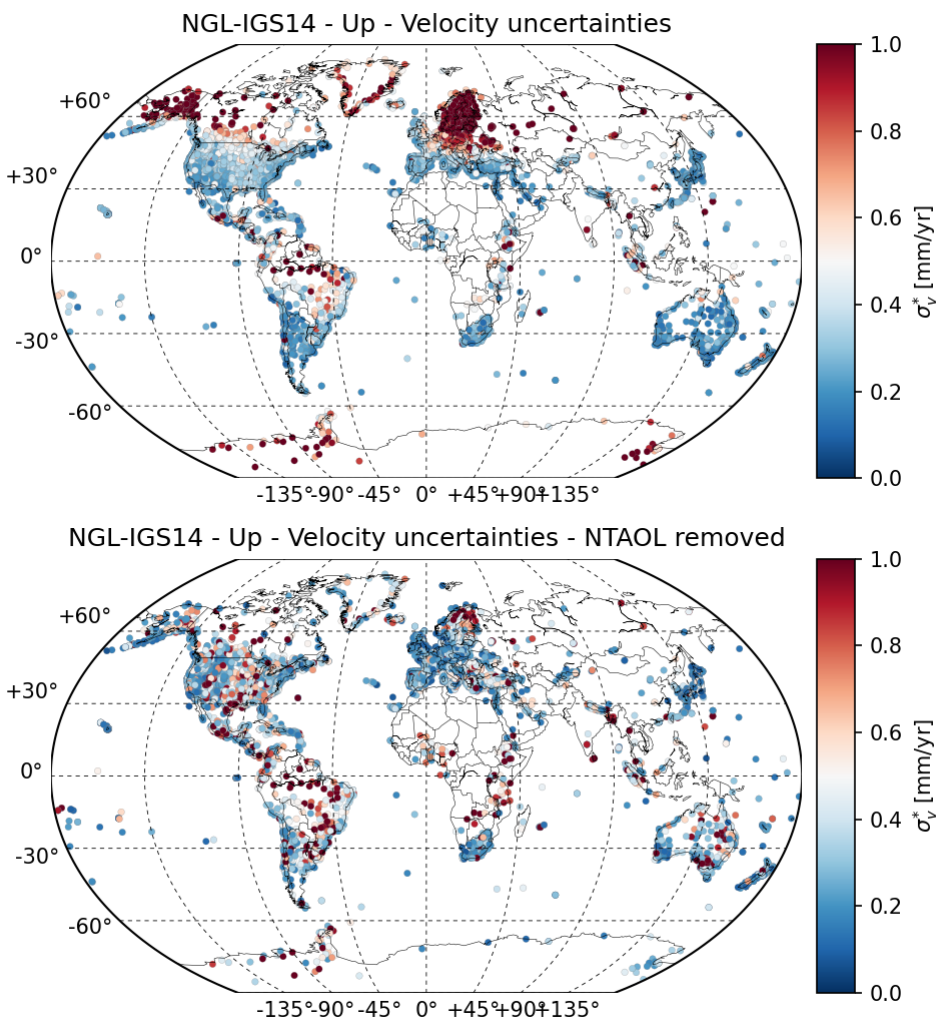

Figure 8. Global variability of the minimum velocity uncertainty for 8-year long time series before removing NTAOL deformations (top) and after removing NTAOL deformations (bottom).
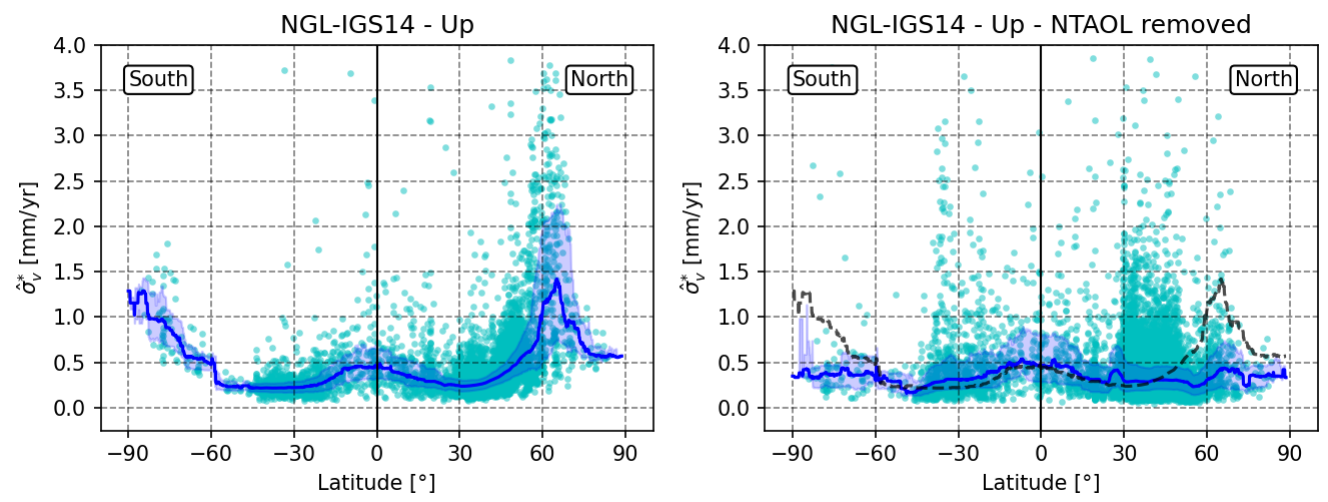

Figure 9. Latitude dependence of the minimum velocity uncertainty for 8-year long time series before (left) and after (right) removing NTAOL deformations. The dots in cyan represent the station-specific estimates. The continuous blue lines represent running medians over $10^{\circ}$ latitude windows. The shaded areas represent the corresponding interquartile ranges. The dashed black lines are the running medians before NTAOL correction, reported on the right plot for comparison with results after NTAOL correction. 


\begin{tabular}{lcccc}
\hline Dataset & $\hat{\bar{\rho}}_{c}$ & $\hat{\bar{\rho}}_{0}$ & $\hat{\bar{\rho}}_{\max }$ & $\hat{\bar{r}}[\mathrm{~km}]$ \\
\hline Raw & 0.01 & 0.40 & 0.41 & 2470 \\
NTAOL removed & 0.02 & 0.27 & 0.29 & 2485
\end{tabular}

Table 1. Parameter estimates obtained by fitting the Gaussian correlation model in Equation 12 to the average spatial correlation estimates.

and the observed change in $\sigma_{v}^{*}$ mostly highlights the incapacity of the $\mathrm{WN}+\mathrm{PL}$ model to retrieve realistic stochastic parameter estimates, hence realistic velocity uncertainties, in the presence of NTAOL deformations.

We note that the dramatic change in velocity uncertainty resulting from NTAOL corrections at high latitudes does not match the minor shift in uncertainty predicted in Santamaría-Gómez and Mémin (2015) from NTAL deformation alone. This difference is because the inadequacy of the $\mathrm{WN}+\mathrm{PL}$ model at high latitudes, and the resulting variance component estimation bias, cannot be observed from the analysis of NTAL deformation time series alone.

Given the dramatic reduction in velocity uncertainty observed at high latitudes, correcting for NTAOL deformation before the estimation of stochastic parameters in GNSS VLM time series will allow a better detection of subtle VLM signals related to glacial isostatic adjustment, present-day ice-melting, and improve sea-level change estimates in these areas.

\subsection{Spatial correlation}

For both the raw and the NTAOL-corrected VLM time series, we computed averaged spatial correlation coefficients $\hat{\rho}\left(t_{k}, d_{l}\right)$ for 200 classes of separation distances $d_{l}$ ranging from $[0,100] \mathrm{km}$ to $[19900,20000] \mathrm{km}$ and for 240 epochs $t_{k}$ between 2008 and 2018. Correlation coefficients between all possible pairs of stations are computed over time windows of 30 days and averaged within each distance class. The resulting time-variable spatial correlation estimates $\hat{\rho}\left(t_{k}, d_{l}\right)$ are presented, for both cases, in Figure 10. To get a clearer picture of the spatial pattern, the spatial correlation averaged over the 2008-2018 period and denoted $\bar{\rho}\left(d_{l}\right)$ is also presented in Figure 10.

Prior to removing NTAOL deformations, the average spatial correlation $\bar{\rho}\left(d_{l}\right)$ is close to +0.45 for short separation distances (that is, $d_{l}<100 \mathrm{~km}$ ) and decreases close to zero for larger separation distances (that is, $d_{l} \geq 5000 \mathrm{~km}$ ). To model this behavior, we approximated the average correlogram $\bar{\rho}\left(d_{l}\right)$ by a Gaussian correlation function defined by

$$
\bar{\rho}\left(d_{l}\right)=\left\{\begin{array}{ll}
1, & d_{l}=0 \\
\bar{\rho}_{c}+\bar{\rho}_{0} \cdot \exp \left(-\left(d_{l} / \bar{r}\right)^{2}\right), & d_{l}>0
\end{array},\right.
$$

where $\bar{\rho}_{c}$ denotes the distance-independent correlation, $\bar{\rho}_{0}$ the distance-variable correlation, and $\bar{r}$ the distance range parameter. According to this Gaussian correlation function, the maximum correlation for $d_{l}>0$ is $\bar{\rho}_{\max }=\bar{\rho}_{c}+\bar{\rho}_{0}$.

The adjusted parameters of the Gaussian correlation function, with and without NTAOL deformations, are presented in Table 1. The graphs corresponding to the adjusted correlation functions are depicted in Figure 10. Although, for the raw VLM resid- 

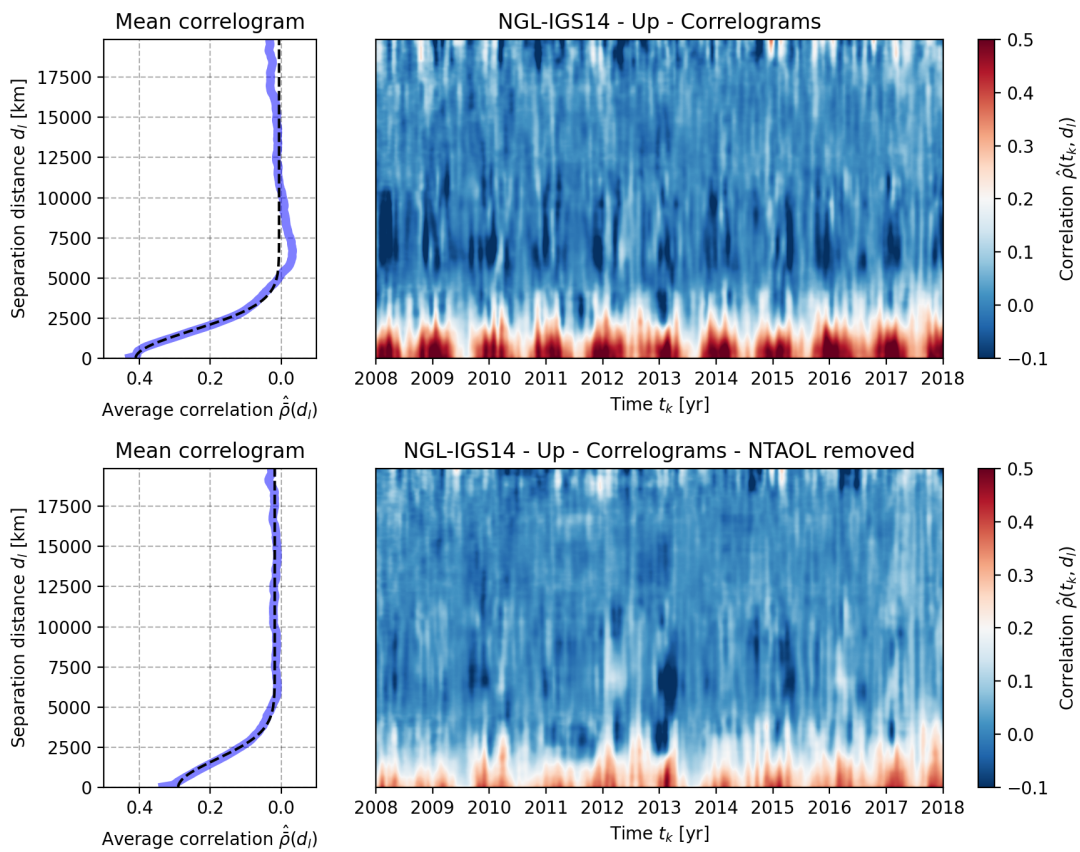

Figure 10. Time-variable spatial correlation estimates $\hat{\rho}\left(t_{k}, d_{l}\right)$ before (top) and after (bottom) removing NTAOL deformations. The blue curves in the left plots represent the average correlograms over the 2008-2018 period. The dashed black lines represent the adjusted Gaussian correlation models (Equation 12).

ual time series, small departures from the observations, inferior to 0.05 , are observed for $d_{l} \geq 5000 \mathrm{~km}$, the Gaussian correlation function is overall a good approximation of the correlation curve for both datasets. After the removal of NTAOL deformations, Table 1 shows that the maximum of correlation for $d_{l}>0.0 \mathrm{~km}$ changed from +0.41 to +0.29 , that is, a reduction of $29.27 \%$. The average range parameter $\bar{r}$ is hardly affected by the NTAOL corrections.

Our results agree with Williams et al. (2004); Amiri-Simkooei et al. (2017) and Benoist et al. (2020), evidencing a spatial correlation of the VLM residual time series. However, our spatial correlations are slightly smaller, most certainly because we analyze over ten thousand recently reprocessed position time series instead of a few hundred (at most).

In addition to the approximately Gaussian average spatial correlation, the timevariable correlograms in Figure 10 reveal an annual oscillation for short separation distances, that is $d_{l}<4000 \mathrm{~km}$, most visible when NTAOL deformations are not removed. The spatial correlation time series $\hat{\rho}\left(t_{k}, d_{l}\right)$ for separation distances of $50 \mathrm{~km}, 950 \mathrm{~km}$, $1950 \mathrm{~km}$, and $3950 \mathrm{~km}$ are presented in Figure 11 to highlight this seasonality. The amplitude of the annual oscillation is maximal for short distances $\left(d_{l}<100 \mathrm{~km}\right)$ and synchronous for all distance classes. Also, both the mean correlation and the annual amplitude get closer to 0.0 for increasing separation distances. To describe the oscillation of $\hat{\rho}\left(t_{k}, d_{l}\right)$, we added an annual modulation to the distance-variable part of the mean Gaussian correlation function of Equation 12, that is

$$
\rho\left(t_{k}, d_{l}\right)= \begin{cases}1, & d_{l}=0 \\ \rho_{c}+\left[\rho_{0}+\rho_{A} \cos \left(\omega_{A} t_{k}-\phi_{A}\right)\right] \cdot \exp \left(-\left(d_{l} / \bar{r}\right)^{2}\right), & d_{l}>0\end{cases}
$$



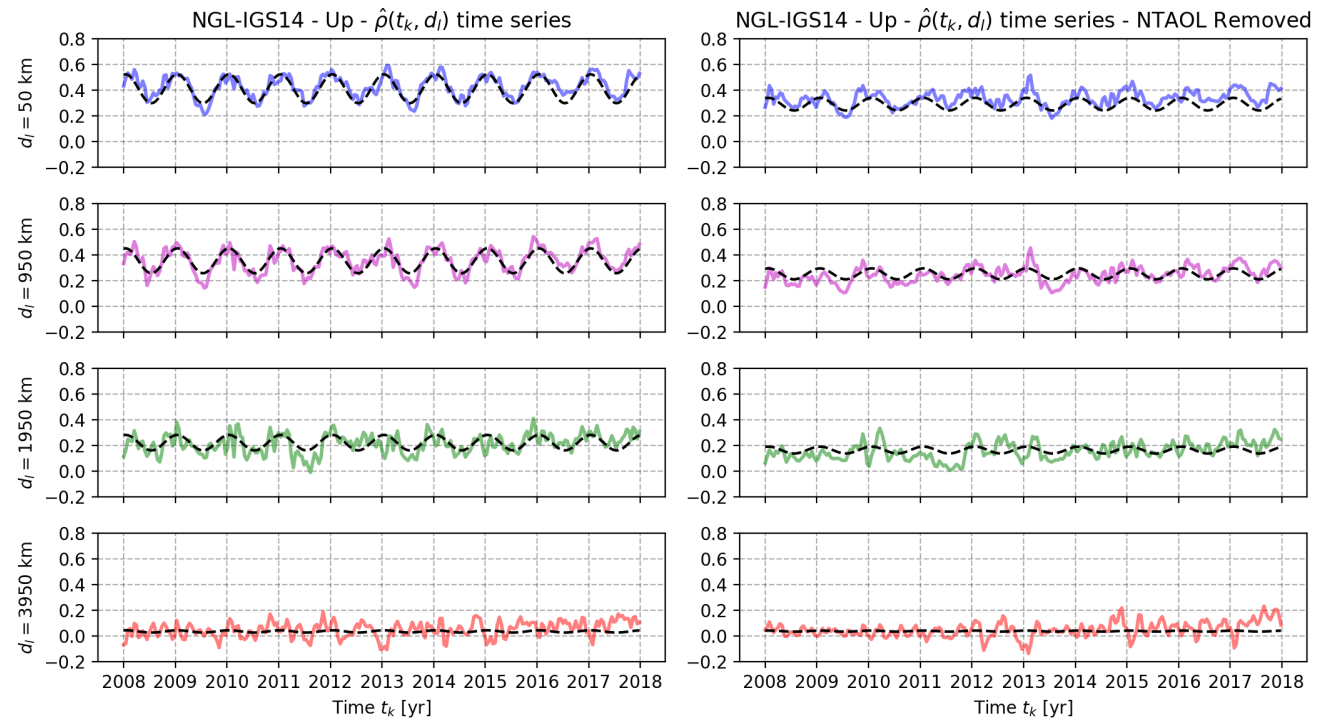

Figure 11. Time-variable spatial correlation estimates $\hat{\rho}\left(t_{k}, d_{l}\right)$ for 4 classes of distances $d_{l}$ before (left) and after (right) removing NTAOL deformations. The colored lines represent the estimates for each class of distance $d_{l}$. The dashed black lines represent the corresponding adjusted time-variable Gaussian correlation function (Equation 13).

\begin{tabular}{lccccccc}
\hline Dataset & $\hat{\rho}_{c}$ & $\hat{\rho}_{0}$ & $\hat{\rho}_{A}$ & $\hat{\phi}_{A}$ [day] & $\hat{\rho}_{\min }$ & $\hat{\rho}_{\max }$ & $\hat{\bar{r}}[\mathrm{~km}]$ \\
\hline Raw & 0.01 & 0.40 & 0.11 & 13.8 & 0.30 & 0.52 & 2469 \\
NTAOL removed & 0.02 & 0.27 & 0.05 & 22.0 & 0.24 & 0.34 & 2485
\end{tabular}

Table 2. Parameter estimates obtained by fitting the seasonal Gaussian spatial correlation model in Equation 13 to the time-variable spatial correlation estimates.

where $\omega_{A}$ is the annual angular frequency, $\rho_{A}$ is the annual amplitude, and $\phi_{A}$ is the corresponding phase. From these estimates, one can define a minimum and a maximum correlation for $d_{l} \approx 0$ as $\rho_{\min }=\rho_{c}+\rho_{0}-\rho_{A}$ and $\rho_{\max }=\rho_{c}+\rho_{0}+\rho_{A}$.

The adjusted parameters of the time-variable correlation model $\hat{\rho}_{c}, \hat{\rho}_{0}, \hat{\rho}_{A}, \hat{\phi}_{A}, \rho_{\min }$ and $\rho_{\max }$, estimated with and without NTAOL correction, are presented in Table 2 . The corresponding graphs are visible in Figure 11.

Prior to NTAOL correction, the spatial correlation at short distances shows an annual amplitude of $\hat{\rho}_{A}=0.11$ and oscillates between +0.30 and +0.52 . According to the estimated phase $\hat{\phi}_{A}$, the minimum of correlation occurs in July and the maximum in January. Since most of the stations analyzed are located in the United States and Europe, the estimated amplitude and phase of this periodicity are certainly more representative of the stochastic variability in these areas but less surely in other parts of the world. After removing NTAOL deformations, we observe a change in annual amplitude, from 0.11 to +0.05 , that is, a $54.55 \%$ reduction. The spatial correlation at short distances then oscillates between +0.24 and +0.34 . The estimated phase $\hat{\phi}_{A}$ remains similar, and the maximum still occurs in January. 
According to the observed reductions, NTAOL deformation is a significant cause of seasonal spatial correlation in GNSS VLM time series. These results support that of Gruszczynski et al. (2019), Männel et al. (2019), and Kreemer and Blewitt (2021), who pointed out that common mode errors in Europe could be due to NTL deformations.

Note that after the NTAOL correction, the spatial correlation at separation distances shorter than $100 \mathrm{~km}$ still oscillates between +0.24 in July and +0.34 in January (e.g., Figure 11 and Table 2). This is expected, as hydrological loading, not corrected in this work, also result in spatially correlated deformation (Van Dam et al., 2001; Tregoning et al., 2009; Chanard et al., 2018). Besides, it is also possible that improving the quality of NTAOL deformation predictions for instance by computing the dynamic ocean response to changes in atmospheric pressure, as done by Mémin et al. (2020), could further reduce the stochastic variability in VLM time series.

Nonetheless, considering that orbit and atmospheric positioning errors are other known sources of spatially correlated stochastic variability (Amiri-Simkooei et al., 2017), it is likely that physical models cannot fully reproduce the spatial correlation in GNSS position time series. Hence, further investigating how the remaining spatial correlation and its seasonality affect the covariance between GNSS station velocities, similarly as Amiri-Simkooei (2009); Razeghi et al. (2016) or Benoist et al. (2020), will undoubtedly benefit the study of small deformation signals in global solutions.

\section{Conclusion}

Characterizing and modeling the stochastic variability in GNSS position time series is essential to reduce the uncertainty on the estimated station velocities. In this study, we investigated how aperiodic non-tidal atmospheric and oceanic loading (NTAOL) deformations influence the stochastic properties of vertical land motion (VLM) time series. To do so, we used 10,151 time series processed by the Nevada Geodetic Laboratory and NTAOL deformation time series provided the Earth System Modelling team at GFZ Potsdam.

We first showed that NTAOL deformations exhibit time correlation describable by a fractionally integrated Gauss-Markov process. Because this behavior cannot be described by the commonly used stochastic model consisting of linear combination of white noise and power-law process, the presence of NTAOL deformations in uncorrected VLM time series results in biases in white noise amplitude, power-law amplitude, and spectral index estimates. In particular, NTAOL deformations cause the power-law parameters to display a strong latitude dependence, resulting in a dramatic increase in velocity uncertainty, exceeding $1.4 \mathrm{~mm} / \mathrm{yr}$ for 8-year long time series, at high latitudes.

Once NTAOL deformations are removed from the VLM time series, we observe a drastic reduction of the latitude dependence of all stochastic parameters. This change is followed by a significant reduction of velocity uncertainty reaching about $70 \%$ in Northern America, Greenland, Fennoscandia, and Antarctica. Therefore, to avoid coping with unrealistically high velocity uncertainties, we advise correcting for NTAOL deformation prior to the estimation of stochastic parameters in GNSS VLM time series. Doing so will certainly allow a better detection of subtle VLM signals related to glacial isostatic adjustment, as well as present-day ice-melting, and improve sea-level change estimates at high latitudes.

In addition to time-correlation, we investigated how NTAOL deformations influence the spatial correlation of aperiodic VLM residuals. First, we demonstrated that, before removing NTAOL deformations, VLM residuals are spatially correlated and that this spatial correlation shows a Gaussian decay with the separation distance, along with a strong seasonality. After removal of NTAOL deformations, the average correlation is 
reduced by $29.3 \%$ and its seasonality by $54.4 \%$, showing that NTAOL deformations are an important source of spatial correlation.

Although NTAOL deformation plays a major role in the stochastic variability in the VLM time series, it does not fully correct for its power-law behavior or its spatial correlation. Therefore, further investigations are still needed to identify the physical and artificial components of the remaining stochastic variability in VLM time series.

\section{Acknowledgments}

The GNSS position time series used in this work can be downloaded at geodesy.unr.edu. The loading deformation time series were obtained from esmdata.gfz-potsdam.de. The authors would like to thank Jim Ray for fruitful discussions about this work, and Thomas Lecocq for his help with the use of the high-performance computing center of the Royal Observatory of Belgium. The authors are also grateful to editor Paul Tregoning, associate editor Annette Eicker, Anna Riddell and an anonymous reviewer for their constructive comments, which significantly improved this manuscript. This study has been financially supported by the Direction Générale de l'Armement (DGA), the Nouvelle-Aquitaine region, and the Centre National des Etudes Spatiales (CNES) as an application of the geodesy missions. This research was also supported by the Brain LASUGEO project entitled "monitoring LAnd SUbsidence caused by Groundwater exploitation through gEOdetic measurements" funded by the Belgian Sciences Policy. This is IPGP contribution number 4214 .

\section{References}

Agnew, D. C. (1992). The time-domain behavior of power-law noises. Geophysical research letters, 19(4), 333-336. doi: https://doi.org/10.1029/91GL02832

Amiri-Simkooei, A. (2007). Least-squares variance component estimation: theory and GPS applications (Unpublished doctoral dissertation). TU Delft, Delft University of Technology.

Amiri-Simkooei, A. (2009). Noise in multivariate GPS position time-series. Journal of Geodesy, 83(2), 175-187. doi: https://doi.org/10.1007/s00190-008-0251-8

Amiri-Simkooei, A. (2013). On the nature of GPS draconitic year periodic pattern in multivariate position time series. Journal of Geophysical Research: Solid Earth, 118(5), 2500-2511. doi: https://doi.org/10.1002/jgrb.50199

Amiri-Simkooei, A. (2016). Non-negative least-squares variance component estimation with application to GPS time series. Journal of Geodesy, 90(5), 451-466. doi: https://doi.org/10.1007/s00190-016-0886-9

Amiri-Simkooei, A., Hosseini-Asl, M., Asgari, J., \& Zangeneh-Nejad, F. (2019). Offset detection in GPS position time series using multivariate analysis. GPS Solutions, 23(1), 13. doi: https://doi.org/10.1007/s10291-018-0805-z

Amiri-Simkooei, A., Mohammadloo, T., \& Argus, D. (2017). Multivariate analysis of GPS position time series of JPL second reprocessing campaign. Journal of Geodesy, 91(6), 685-704. doi: https://doi.org/10.1007/s00190-016-0991-9

Amiri-Simkooei, A., Tiberius, C., \& Teunissen, s. P. (2007). Assessment of noise in GPS coordinate time series: methodology and results. Journal of Geophysical Research: Solid Earth, 112(B7). doi: https://doi.org/10.1029/2006JB004913

Baarda, W. (1968). A testing procedure for use in geodetic networks. Publication on Geodesy, New Series, 2.

Ballu, V., Gravelle, M., Wöppelmann, G., de Viron, O., Rebischung, P., Becker, M., \& Sakic, P. (2019). Vertical land motion in the Southwest and Central Pacific from available GNSS solutions and implications for relative sea levels. Geophysical Journal International, 218(3), 1537-1551. doi: https://doi.org/10.1093/gji/ggz247 
Benoist, C., Collilieux, X., Rebischung, P., Altamimi, Z., Jamet, O., Métivier, L., ... Bel, L. (2020). Accounting for spatiotemporal correlations of GNSS coordinate time series to estimate station velocities. Journal of Geodynamics, 101693. doi: https://doi.org/10.1016/j.jog.2020.101693

Bertiger, W., Bar-Sever, Y., Dorsey, A., Haines, B., Harvey, N., Hemberger, D., ... others (2020). GipsyX/RTGx, A New Tool Set for Space Geodetic Operations and Research. Advances in Space Research. doi: https://doi.org/10.1016/ j.asr.2020.04.015

Bevis, M., \& Brown, A. (2014). Trajectory models and reference frames for crustal motion geodesy. Journal of Geodesy, 88(3), 283-311. doi: https://doi.org/10 .1007/s00190-013-0685-5

Blewitt, G. (2003). Self-consistency in reference frames, geocenter definition, and surface loading of the solid Earth. Journal of geophysical research: solid earth, 108(B2). doi: https://doi.org/10.1029/2002JB002082

Blewitt, G., Hammond, W. C., \& Kreemer, C. (2018). Harnessing the GPS data explosion for interdisciplinary science. Eos, 99, 1-2. doi: https://doi.org/10 $.1029 / 2018 \mathrm{EO} 104623$

Blewitt, G., \& Lavallée, D. (2002). Effect of annual signals on geodetic velocity. Journal of Geophysical Research: Solid Earth, 107(B7), ETG-9. doi: https:// doi.org/10.1029/2001JB000570

Boehm, J., Werl, B., \& Schuh, H. (2006). Troposphere mapping functions for GPS and very long baseline interferometry from European Centre for MediumRange Weather Forecasts operational analysis data. Journal of geophysical research: solid earth, 111(B2). doi: https://doi.org/10.1029/2005JB003629

Böhm, J., Niell, A., Tregoning, P., \& Schuh, H. (2006). Global Mapping Function (GMF): A new empirical mapping function based on numerical weather model data. Geophysical Research Letters, 33(7). doi: https://doi.org/10.1029/ 2005GL025546

Bos, M., Fernandes, R., Williams, S., \& Bastos, L. (2008). Fast error analysis of continuous GPS observations. Journal of Geodesy, 82(3), 157-166. doi: https:// doi.org/10.1007/s00190-007-0165-x

Bos, M., Montillet, J.-P., Williams, S., \& Fernandes, R. M. (2020). Introduction to Geodetic Time Series Analysis. In Geodetic Time Series Analysis in Earth Sciences (pp. 29-52). Springer.

Calais, E. (1999). Continuous GPS measurements across the Western Alps, 19961998. Geophysical Journal International, 138(1), 221-230. doi: https://doi .org/10.1046/j.1365-246x.1999.00862.x

Chanard, K., Fleitout, L., Calais, E., Rebischung, P., \& Avouac, J.-P. (2018). Toward a global horizontal and vertical elastic load deformation model derived from GRACE and GNSS station position time series. Journal of Geophysical Research: Solid Earth, 123(4), 3225-3237. doi: https://doi.org/10.1002/ 2017JB015245

Craig, T. J., \& Calais, E. (2014). Strain accumulation in the New Madrid and Wabash Valley seismic zones from 14 years of continuous GPS observation. Journal of Geophysical Research: Solid Earth, 119(12), 9110-9129. doi: https://doi.org/10.1002/2014JB011498

Dach, R., Böhm, J., Lutz, S., Steigenberger, P., \& Beutler, G. (2011). Evaluation of the impact of atmospheric pressure loading modeling on GNSS data analysis. Journal of geodesy, 85(2), 75-91. doi: https://doi.org/10.1007/ s00190-010-0417-z

Dill, R., \& Dobslaw, H. (2013). Numerical simulations of global-scale high-resolution hydrological crustal deformations. Journal of Geophysical Research: Solid Earth, 118(9), 5008-5017. doi: https://doi.org/10.1002/jgrb.50353

Elliott, J., Walters, R., \& Wright, T. (2016). The role of space-based observation in understanding and responding to active tectonics and earthquakes. Nature 
communications, 7(1), 1-16. doi: https://doi.org/10.1038/ncomms13844

Gazeaux, J., Williams, S., King, M., Bos, M., Dach, R., Deo, M., ... others (2013). Detecting offsets in GPS time series: First results from the detection of offsets in GPS experiment. Journal of Geophysical Research: Solid Earth, 118(5), 2397-2407. doi: https://doi.org/10.1002/jgrb.50152

Gegout, P., Boy, J.-P., Hinderer, J., \& Ferhat, G. (2010). Modeling and observation of loading contribution to time-variable GPS sites positions. In Gravity, geoid and earth observation (pp. 651-659). Springer. doi: https://doi.org/10.1007/ 978-3-642-10634-7_86

Gruszczynski, M., Klos, A., \& Bogusz, J. (2019). A filtering of incomplete GNSS position time series with probabilistic Principal Component Analysis. In Geodynamics and Earth Tides Observations from Global to Micro Scale (pp. 247-273). Springer. doi: https://doi.org/10.1007/s00024-018-1856-3

Husson, L., Bodin, T., Spada, G., Choblet, G., \& Kreemer, C. (2018). Bayesian surface reconstruction of geodetic uplift rates: Mapping the global fingerprint of Glacial Isostatic Adjustment. Journal of Geodynamics, 122, 25-40. doi: https://doi.org/10.1016/j.jog.2018.10.002

Kennett, B. L., Engdahl, E., \& Buland, R. (1995). Constraints on seismic velocities in the Earth from traveltimes. Geophysical Journal International, 122(1), 108124. doi: https://doi.org/10.1111/j.1365-246X.1995.tb03540.x

Klos, A., \& Bogusz, J. (2017). An evaluation of velocity estimates with a correlated noise: case study of IGS ITRF2014 European stations. Acta Geodynamica et Geomaterialia, 14(3), 255-265. doi: https://doi.org/10.13168/AGG.2017 .0009

Klos, A., Bogusz, J., Bos, M. S., \& Gruszczynska, M. (2020). Modelling the GNSS time series: different approaches to extract seasonal signals. In Geodetic Time Series Analysis in Earth Sciences (pp. 211-237). Springer. doi: https://doi .org/10.1007/978-3-030-21718-1_7

Klos, A., Bogusz, J., Figurski, M., \& Kosek, W. (2015). On the handling of outliers in the GNSS time series by means of the noise and probability analysis. In IAG 150 Years (pp. 657-664). Springer. doi: https://doi.org/10.1007/1345 _2015_78

Klos, A., Bos, M. S., Fernandes, R. M., \& Bogusz, J. (2019). Noise-dependent adaption of the Wiener filter for the GPS position time series. Mathematical Geosciences, 51 (1), 53-73. doi: https://doi.org/10.1007/s11004-018-9760-z

Klos, A., Dobslaw, H., Dill, R., \& Bogusz, J. (2021). Identifying the sensitivity of GPS to non-tidal loadings at various time resolutions: examining vertical displacements from continental Eurasia. GPS Solutions, 25(3), 1-17. doi: https://doi.org/10.1007/s10291-021-01135-w

Koch, K. (1986). Maximum likelihood estimate of variance components. Bulletin Gaodésique, 60(4), 329-338. doi: https://doi.org/10.1007/BF02522340

Kreemer, C., \& Blewitt, G. (2021). Robust estimation of spatially varying commonmode components in GPS time-series. Journal of Geodesy, 95(1), 1-19. doi: https://doi.org/10.1007/s00190-020-01466-5

Kreemer, C., Blewitt, G., \& Davis, P. M. (2020). Geodetic evidence for a buoyant mantle plume beneath the Eifel volcanic area, NW Europe. Geophysical Journal International, 222(2), 1316-1332. doi: https://doi.org/10.1093/gji/ ggaa227

Langbein, J. (2004). Noise in two-color electronic distance meter measurements revisited. Journal of Geophysical Research: Solid Earth, 109(B4). doi: https:// doi.org/10.1029/2003JB002819

Langbein, J. (2008). Noise in GPS displacement measurements from Southern California and Southern Nevada. Journal of Geophysical Research: Solid Earth, 113(B5). doi: https://doi.org/10.1029/2007JB005247

Langbein, J. (2017). Improved efficiency of maximum likelihood analysis of time 
series with temporally correlated errors. Journal of Geodesy, 91(8), 985-994. doi: https://doi.org/10.1007/s00190-017-1002-5

Langbein, J., \& Svarc, J. L. (2019). Evaluation of temporally correlated noise in Global Navigation Satellite System time series: Geodetic monument performance. Journal of Geophysical Research: Solid Earth, 124(1), 925-942. doi: https://doi.org/10.1029/2018JB016783

Männel, B., Dobslaw, H., Dill, R., Glaser, S., Balidakis, K., Thomas, M., \& Schuh, H. (2019). Correcting surface loading at the observation level: impact on global GNSS and VLBI station networks. Journal of Geodesy, 93(10), 20032017. doi: https://doi.org/10.1007/s00190-019-01298-y

Mao, A., Harrison, C. G., \& Dixon, T. H. (1999). Noise in GPS coordinate time series. Journal of Geophysical Research: Solid Earth, 104(B2), 2797-2816. doi: https://doi.org/10.1029/1998JB900033

Martens, H. R., Argus, D. F., Norberg, C., Blewitt, G., Herring, T. A., Moore, A. W., ... Kreemer, C. (2020). Atmospheric pressure loading in GPS positions: dependency on GPS processing methods and effect on assessment of seasonal deformation in the contiguous USA and Alaska. Journal of Geodesy, 94 (12), 1-22. doi: https://doi.org/10.1007/s00190-020-01445-w

Masson, C., Mazzotti, S., Vernant, P., \& Doerflinger, E. (2019). Extracting small deformation beyond individual station precision from dense Global Navigation Satellite System (GNSS) networks in France and western Europe. Solid Earth, 10 (6), 1905-1920. doi: https://doi.org/10.5194/se-10-1905-2019

Mémin, A., Boy, J.-P., \& Santamaria-Gomez, A. (2020). Correcting GPS measurements for non-tidal loading. GPS Solutions, 24(2), 1-13. doi: https://doi.org/ 10.1007/s00190-010-0376-4

Nocquet, J.-M., Calais, E., \& Parsons, B. (2005). Geodetic constraints on glacial isostatic adjustment in Europe. Geophysical Research Letters, 32(6). doi: https://doi.org/10.1029/2004GL022174

Petit, G., \& Luzum, B. (2010). IERS conventions (2010) (Tech. Rep.). Bureau International des Poids et Mesures, Sevres (France). Retrieved from https :// apps.dtic.mil/sti/citations/ADA535671

Pfeffer, J., \& Allemand, P. (2016). The key role of vertical land motions in coastal sea level variations: a global synthesis of multisatellite altimetry, tide gauge data and GPS measurements. Earth and Planetary Science Letters, 439, 39-47. doi: https://doi.org/10.1016/j.epsl.2016.01.027

Ray, J., Altamimi, Z., Collilieux, X., \& van Dam, T. (2008). Anomalous harmonics in the spectra of GPS position estimates. GPS solutions, 12(1), 55-64. doi: https://doi.org/10.1007/s10291-007-0067-7

Ray, J., Griffiths, J., Collilieux, X., \& Rebischung, P. (2013). Subseasonal GNSS positioning errors. Geophysical Research Letters, 40(22), 5854-5860. doi: https:// doi.org/10.1002/2013GL058160

Razeghi, S., Amiri-Simkooei, A., \& Sharifi, M. (2016). Coloured noise effects on deformation parameters of permanent GPS networks. Geophysical journal international, 204 (3), 1843-1857. doi: https://doi.org/10.1093/gji/ggv499

Santamaría-Gómez, A., Bouin, M.-N., Collilieux, X., \& Wöppelmann, G. (2011). Correlated errors in GPS position time series: Implications for velocity estimates. Journal of Geophysical Research: Solid Earth, 116(B1). doi: https://doi.org/10.1029/2010JB007701

Santamaría-Gómez, A., \& Mémin, A. (2015). Geodetic secular velocity errors due to interannual surface loading deformation. Geophysical Journal International, 202(2), 763-767. doi: https://doi.org/10.1093/gji/ggv190

Santamaría-Gómez, A., \& Ray, J. (2021). Chameleonic noise in GPS position time series. Journal of Geophysical Research: Solid Earth, 126(3), e2020JB019541. doi: https://doi.org/10.1029/2020JB019541

Schumacher, M., King, M., Rougier, J., Sha, Z., Khan, S. A., \& Bamber, J. (2018). 
A new global GPS data set for testing and improving modelled GIA uplift rates. Geophysical Journal International, 214(3), 2164-2176. doi: https://doi.org/10.1093/gji/ggy235

Selle, C., Desai, S., Garcia Fernandez, M., \& Sibois, A. (2014). Spectral analysis of GPS-based station positioning time series from PPP solutions. In 2014 IGS workshop. Pasadena, CA, USA.

Steigenberger, P., Boehm, J., \& Tesmer, V. (2009). Comparison of GMF/GPT with VMF1/ECMWF and implications for atmospheric loading. Journal of Geodesy, 83(10), 943. doi: https://doi.org/10.1007/s00190-009-0311-8

Teunissen, P. (1988). Towards a least-squares framework for adjusting and testing of both functional and stochastic models.

Teunissen, P. (2000a). Adjustment theory, Series on Mathematical geodesy and positioning. Delft University Press.

Teunissen, P. (2000b). Testing theory an introduction, Series on Mathematical geodesy and positioning. Delft University Press.

Teunissen, P., \& Amiri-Simkooei, A. (2008). Least-squares variance component estimation. Journal of geodesy, 82(2), 65-82. doi: https://doi.org/10.1007/s00190 $-007-0157-\mathrm{x}$

Tregoning, P., \& van Dam, T. (2005). Atmospheric pressure loading corrections applied to GPS data at the observation level. Geophysical Research Letters, 32(22). doi: https://doi.org/10.1029/2005GL024104

Tregoning, P., \& Watson, C. (2009). Atmospheric effects and spurious signals in GPS analyses. Journal of Geophysical Research: Solid Earth, 114(B9). doi: https://doi.org/10.1029/2009JB006344

Tregoning, P., Watson, C., Ramillien, G., McQueen, H., \& Zhang, J. (2009). Detecting hydrologic deformation using GRACE and GPS. Geophysical Research Letters, 36(15). doi: https://doi.org/10.1029/2009GL038718

Van Camp, M., Williams, S., \& Francis, O. (2005). Uncertainty of absolute gravity measurements. Journal of Geophysical Research: Solid Earth, 110(B5). doi: https://doi.org/10.1029/2004JB003497

Van Dam, T., Blewitt, G., \& Heflin, M. (1994). Detection of atmospheric pressure loading using the Global Positioning System. Journal of Geophysical Research, 99(B12), 23939-23950. Retrieved from http://hdl.handle.net/10993/685

Van Dam, T., Collilieux, X., Wuite, J., Altamimi, Z., \& Ray, J. (2012). Nontidal ocean loading: amplitudes and potential effects in GPS height time series. Journal of Geodesy, 86(11), 1043-1057. doi: https://doi.org/10.1007/ s00190-012-0564-5

Van Dam, T., \& Wahr, J. (1987). Displacements of the Earth's surface due to atmospheric loading: Effects on gravity and baseline measurements. Journal of Geophysical Research: Solid Earth, 92(B2), 1281-1286.

Van Dam, T., Wahr, J., Milly, P., Shmakin, A., Blewitt, G., Lavallée, D., \& Larson, K. (2001). Crustal displacements due to continental water loading. Geophysical Research Letters, 28(4), 651-654. doi: https://doi.org/10.1029/ 2000GL012120

Wackernagel, H. (2013). Multivariate geostatistics: an introduction with applications. Springer Science \& Business Media.

Wdowinski, S., Bock, Y., Zhang, J., Fang, P., \& Genrich, J. (1997). Southern California permanent GPS geodetic array: Spatial filtering of daily positions for estimating coseismic and postseismic displacements induced by the 1992 Landers earthquake. Journal of Geophysical Research: Solid Earth, 102(B8), 18057-18070. doi: https://doi.org/10.1029/97JB01378

Williams, S. (2003a). The effect of coloured noise on the uncertainties of rates estimated from geodetic time series. Journal of Geodesy, 76 (9-10), 483-494. doi: https://doi.org/10.1007/s00190-002-0283-4

Williams, S. (2003b). Offsets in global positioning system time series. Journal 
of Geophysical Research: Solid Earth, 108(B6). doi: https://doi.org/10.1029/ 2002JB002156

Williams, S. (2008). CATS: GPS coordinate time series analysis software. GPS solutions, 12(2), 147-153. doi: https://doi.org/10.1007/s10291-007-0086-4

Williams, S., Bock, Y., Fang, P., Jamason, P., Nikolaidis, R. M., Prawirodirdjo, L., ... Johnson, D. J. (2004). Error analysis of continuous GPS position time series. Journal of Geophysical Research: Solid Earth, 109(B3). doi: https://doi.org/10.1029/2003JB002741

Williams, S., \& Penna, N. (2011). Non-tidal ocean loading effects on geodetic GPS heights. Geophysical Research Letters, 38(9). doi: https://doi.org/10.1029/ 2011GL046940

Wöppelmann, G., \& Marcos, M. (2016). Vertical land motion as a key to understanding sea level change and variability. Reviews of Geophysics, 54 (1), 64-92. doi: https://doi.org/10.1002/2015RG000502

Wöppelmann, G., Miguez, B. M., Bouin, M.-N., \& Altamimi, Z. (2007). Geocentric sea-level trend estimates from GPS analyses at relevant tide gauges worldwide. Global and Planetary Change, 57(3-4), 396-406. doi: https://doi.org/ 10.1016/j.gloplacha.2007.02.002

Zhang, J., Bock, Y., Johnson, H., Fang, P., Williams, S., Genrich, J., ... Behr, J. (1997). Southern California Permanent GPS Geodetic Array: Error analysis of daily position estimates and site velocities. Journal of geophysical research: solid earth, 102(B8), 18035-18055. doi: https://doi.org/10.1029/97JB01380

Zumberge, J., Heflin, M., Jefferson, D., Watkins, M., \& Webb, F. (1997). Precise point positioning for the efficient and robust analysis of GPS data from large networks. Journal of geophysical research: solid earth, 102(B3), 5005-5017. doi: https://doi.org/10.1029/96JB03860 